\author{
UNIVERSIDADE DE SÃO PAULO \\ FACULDADE DE MEDICINA DE RIBEIRÃO PRETO \\ DEPARTAMENTO DE MEDICINA SOCIAL \\ PROGRAMA DE PÓS-GRADUAÇÃO EM SAÚDE NA COMUNIDADE
}

BIANCA BARTHOLO JULIO

\title{
Estilo de Vida e Classificação do Estado \\ Nutricional de Usuários das Estratégias de Saúde da Família de um Município do Interior Paulista
}

Ribeirão Preto

2018 



\section{Estilo de Vida e Classificação do Estado Nutricional de Usuários das Estratégias de Saúde da Família de um Município do Interior Paulista}

Dissertação apresentada à Faculdade de Medicina de Ribeirão Preto da Universidade de São Paulo para obtenção do título de Mestre em Ciências pelo Programa de Pós-Graduação em Saúde na comunidade.

Orientador: Prof. Dr. Laércio Joel Franco 

Autorizo a reprodução e divulgação total ou parcial deste trabalho, por qualquer meio convencional ou eletrônico, para fins de estudo e pesquisa, desde que citada a fonte.

Júlio, Bianca Bartholo

Estilo de vida e classificação do estado nutricional de usuários das estratégias de saúde da família de um município do interior paulista. Ribeirão Preto, 2018. 73 p. : il. ; $30 \mathrm{~cm}$

Dissertação de Mestrado, apresentada à Faculdade de Medicina de Ribeirão Preto/USP. Área de concentração: Saúde na Comunidade.

Orientador: Prof. Dr. Laércio Joel Franco.

1. Estilo de Vida 2. Obesidade 3. Sobrepeso 4. e Estratégia de Saúde da Família. 

Nome: JULIO, Bianca Bartholo

Título: Estilo de Vida e Classificação do Estado Nutricional de Usuários das Estratégias de Saúde da Família de um Município do Interior Paulista

Aprovado em: de de

\section{Banca Examinadora}

Prof. Dr.

Instituição:

Julgamento:

Prof. Dr.

Instituição:

Julgamento:

Prof. Dr.

Instituição:

Julgamento: 



\section{Agradecimentos}

A Deus, que está acima de tudo em minha vida, responsável por auxiliar e guiar me nas horas mais difíceis.

Aos meus pais pelo apoio, presença, dedicação, paciência, amor e carinho. Por me ensinar a importância do estudo e estimular minha capacidade de pensar.

Meu orientador Dr. Laércio Joel Franco, pelo aceite, paciência, incentivo e disponibilidade de tempo.

Aos amigos que conquistei nesse percurso e em especial Fernando Peixoto pelo auxílio, acolhimento, incentivo e pelas críticas construtivas.

A minha amiga Tuane e família Luz, pelo acolhimento, carinho e doação, sem ele seria impossível de chegar até aqui.

Ao meu namorado Renan Furlan, por sua paciência, carinho, disponibilidade e incentivo nas horas mais difíceis e por todos os dias de compreensão e auxílio técnico nas madrugadas.

A minha tia Daniela Bartholo, por sempre estar presente em todas conquistas e insucessos de minha vida, oferecendo apoio, carinho e incentivo. Exemplo que quero seguir, como profissional.

A minha tia Fernanda Tanganeli que sempre está disposta a ajudar e oferecer palavras positivas em momentos difíceis.

A toda minha família pela paciência e respeito no pedido sincero de silêncio.

A todos os professores do departamento que foram essenciais para meu desenvolvimento humano e profissional, possibilitando troca de experiência, conhecimento profundo e vivências inesquecíveis.

Aos amigos de minha cidade natal Bebedouro-SP, pelo apoio, carinho, compreensão e incentivo. 



\section{Resumo}

Julio, B.B. Estilo de vida e classificação do estado nutricional de usuários das estratégias de saúde da família de um município do interior paulista. 2018. 73 p. Dissertação de Mestrado - Faculdade de Medicina de Ribeirão Preto. Universidade de São Paulo - FMRP - USP, Ribeirão Preto, 2018.

O estilo de vida adotado pela população como má alimentação, sedentarismo e poucas horas de sono podem contribuir para o aumento de peso e consequentemente para o aparecimento de doenças crônicas não transmissíveis. O objetivo deste estudo foi avaliar o estado nutricional e identificar o estilo de vida da população adulta usuária da Estratégia de Saúde da Família (ESF) de um município paulista. Foi conduzido um inquérito com emprego de questionário aplicado pelo pesquisador em entrevistas individualizadas, com 381 pessoas maiores de vinte anos em onze ESF do município de Bebedouro-SP. A coleta de dados foi realizada no prazo de oito meses (Outubro de 2016 a Maio de 2017), com participantes que encontravam presentes no local, nos dias visitados, até atingir a cota amostral prevista para a unidade. Foram realizadas medidas antropométricas (peso, altura e IMC) e aplicado os questionários sobre estilo de vida e o socioeconômico e demográfico em todos os participantes. Observou-se predomínio dos participantes da faixa etária 20 - 39 anos (33,9\%), do sexo feminino $(74,5 \%)$, com ensino médio completo/superior incompleto (38,6\%), classe econômica D-E $(59,5 \%)$ hábito de sono menor que 6 horas/dia $(41,5 \%)$ e sedentários $(66,9 \%)$. Em relação ao consumo alimentar, a maioria consumia feijão todos os dias $(33,6 \%)$, com diferença estatística significante entre adultos e idosos (limite inferior: 0,59 e limite superior: 0,03 ) e também na comparação do estado nutricional de sobrepeso e obesidade (limite inferior: 0,21 e limite superior: 1,37). Quanto ao estado nutricional, classificado de acordo com o índice de massa corporal, verificou-se que a maioria dos adultos apresentavam obesidade $(43,5 \%)$ e sobrepeso $(37,4 \%)$ e a maioria dos idosos $(61,8 \%)$ sobrepeso. Em resumo, a população que mais frequenta as unidades de ESF do município estudado era do sexo feminino, da faixa etária dos 20 aos 39 anos, com vida sedentária, entretanto não faz ingestão de álcool e tabaco. O excesso de peso predominou nos adultos e idosos.

Palavras-chave: Estilo de Vida, Obesidade, Sobrepeso, Estratégia de Saúde da Família 


\section{Abstract}

Julio, B.B. Lifestyle and classification oh the nutricional status of users of the Family health strategy of a municipality in the countryside of São Paulo. 2018. 73 p. Dissertation (Mater). Ribeirão Preto Medical School. University of São Paulo. Ribeirão Preto, 2018.

The lifestyle adopted by the population as poor diet, sedentary lifestyle and few hours of sleep can contribute to weight gain and consequently for the occurrence of chronic non-communicable diseases. The aim of this study was to evaluate the nutritional status and identify the lifestyle of the adult population using the family health strategy in a municipality of the countryside of São Paulo State. A survey was conducted using a questionnaire applied by the researcher in individualized interviews, with 381 individuals aged twenty years or more, in eleven Family Health Strategies in the municipality of Bebedouro-SP. Data collection was carried out within eight months (October 2016 to May 2017), with participants who were present in the site, on the visited days, until to complete the sampling quota of the unit. Anthropometric measurements (weight, height and BMI) were performed, and a lifestyle and socioeconomic and demographic questionnaires were applied to all participants. Among participants, there was predominance of the categories age group 20 - 39 years old $(33.9 \%)$, female $(74.5 \%)$, married $(50.9 \%)$, incomplete high school $(38.6 \%)$, economic class D and E (59.5\%), having a sleep habit of less than 6 hours / day $(41.5 \%)$ and sedentary $(66.9 \%)$. In relation to food consumption, most of the participants consumed beans every day 33.6\%) with significant statistical difference between adults and the elderly (lower limit: 0.59 and upper limit: 0.03 ) and also in the comparison of the nutritional status of overweight and obesity (lower limit: 0.21 and upper limit superior: 1,37). In relation to the nutritional status, classified according to body mass index, the majority of adults were obese $(43.5 \%)$ and overweight $(37.4 \%)$ and the majority of elderly $(61.8 \%)$ were overweight. In summary, the population that most visit the ESF units of the studied municipality was female, from the age group of 20 to 39 years old, with a sedentary life, but does not consume alcohol and tobacco. Excess weight predominated in adults and elderly.

Keywords: Lifestyle, Obesity, Overweight, Family Health Strategy 



\section{Lista de siglas}

$\begin{array}{ll}\text { ABEP } & \text { Associação Brasileira de Empresas de Pesquisa } \\ \text { CDC } & \text { Centers for Disease Control and Prevention } \\ \text { DCNT } & \text { Doenças Crônicas não Transmissíveis } \\ \text { ESF } & \text { Estratégia de Saúde da Família } \\ \text { IBGE } & \text { Instituto Brasileiro de Geografia e Estatística } \\ \text { IMC } & \text { Índice de Massa Corporal } \\ \text { Kg } & \text { Quilograma } \\ \text { MI } & \text { Mililitro } \\ \text { NASF } & \text { Núcleo de Apoio a Saúde da Família } \\ \text { OMS } & \text { Organização Mundial de Saúde } \\ \text { PNAD } & \text { Pesquisa Nacional por Amostra de Domicílio } \\ \text { PNS } & \text { Pesquisa Nacional de Saúde } \\ \text { SIAB } & \text { Sistema de Informação da Atenção Básica } \\ \text { TCLE } & \text { Termo de Consentimento Livre e Esclarecido } \\ \text { TV } & \text { Televisão } \\ \text { VIGITEL } & \text { Vigilância de Fatores de Risco e Proteção para Doenças Crônicas }\end{array}$





\section{Lista de tabelas}

TABELA 1 - UNIDADES DE ESF DE BEBEDOURO ESTRATIFICADAS POR NÚMERO DE USUÁRIOS, PARA CÁLCULO DO TAMANHO DA AMOSTRA.

TABELA 2 - DISTRIBUIÇÃO DA POPULAÇÃO ESTUDADA, DE ACORDO COM FAIXA ETÁRIA, SEXO, ESTADO CIVIL E ESCOLARIDADE. BEBEDOURO, 2017 34

TABELA 3 - FREQUÊNCIA DO CONSUMO ALIMENTAR, POR NÚMERO DE DIAS DA SEMANA, NA POPULAÇÃO ADULTA QUE UTILIZA A ESF DE BEBEDOURO, 2017 .38

Tabela 4 - Frequência do Consumo de Gordura Aparente da Carne e Pele de FRANGO ENTRE USUÁRIOS ADULTOS DA ESF DE BEBEDOURO, 2017. 40

TABELA 5 - EstAdo NUTRICIONAL SEGUNDO IMC, EM USUÁRIOS ADULTOS E IDOSOS, SEGUNDO O SEXO, QUE UTILIZAM A ESF DE BEBEDOURO, 2017 44 



\section{Sumário}

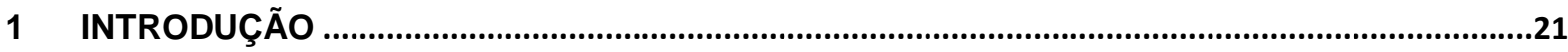

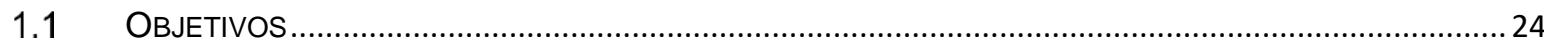

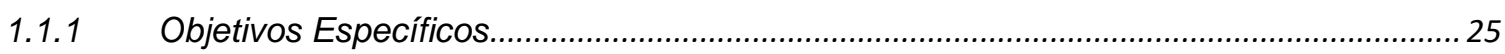

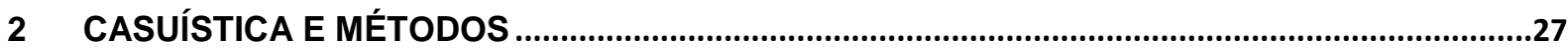

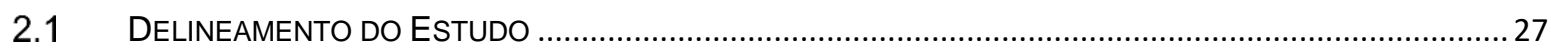

2.2 CONTEXTO

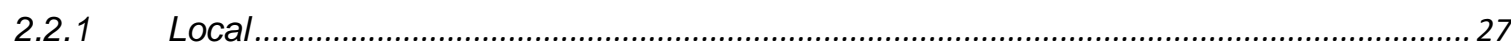

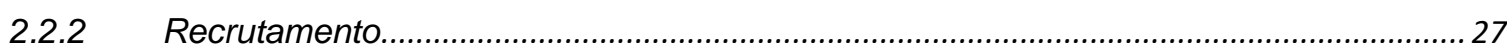

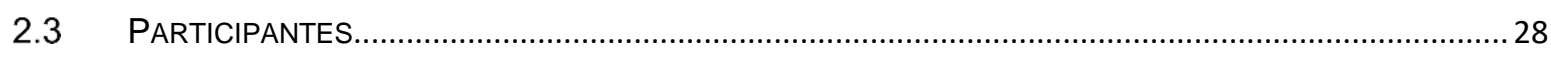

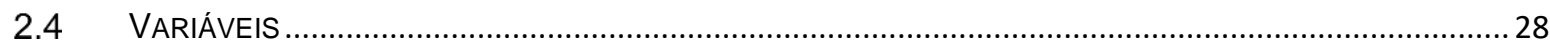

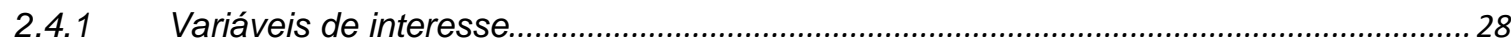

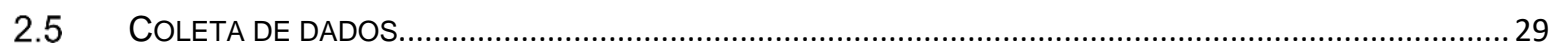

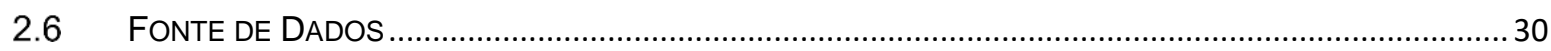

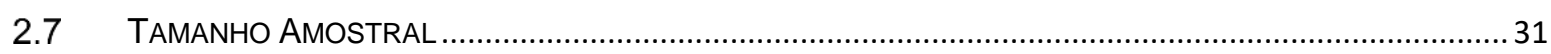

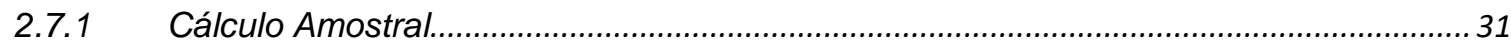

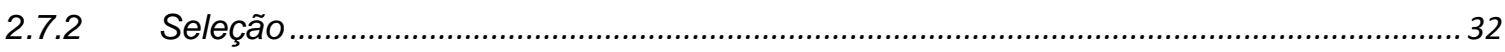

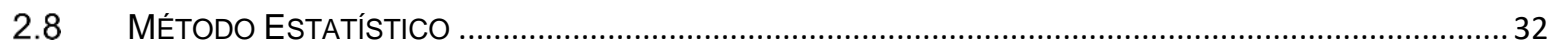

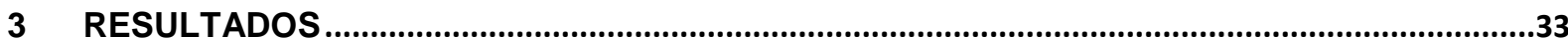

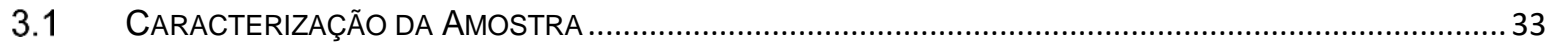

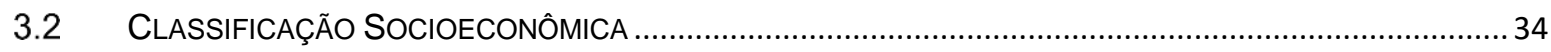

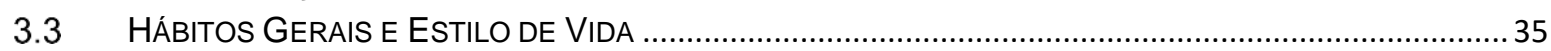

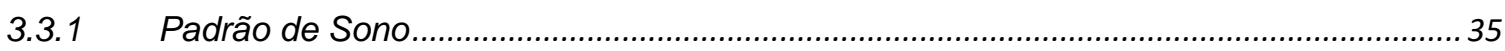

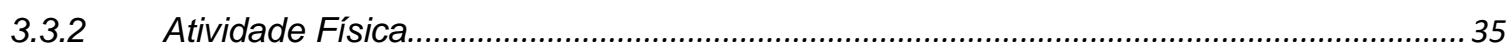

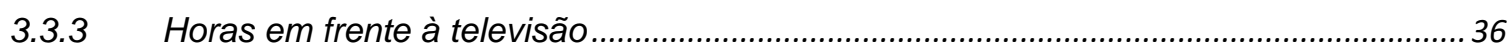

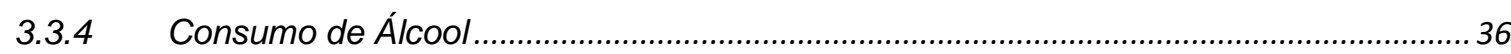

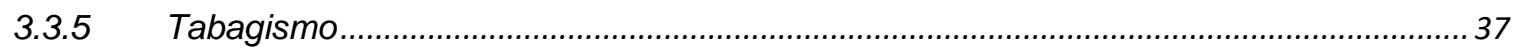

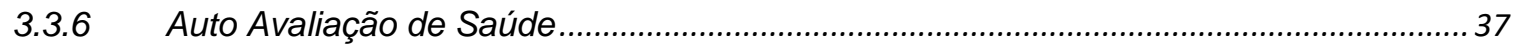

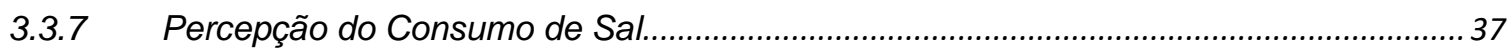

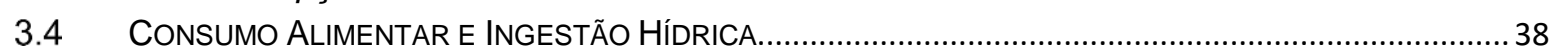

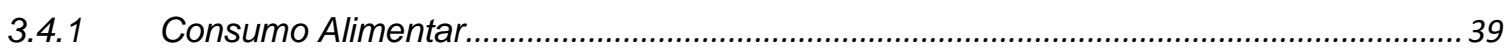

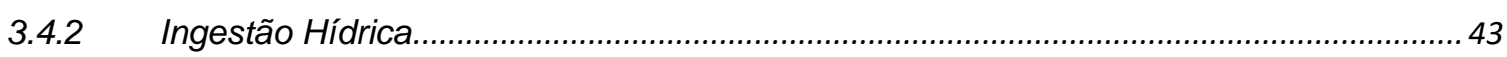

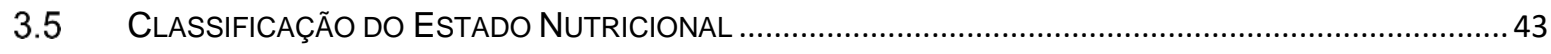

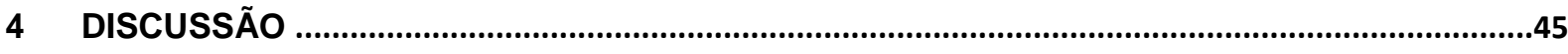

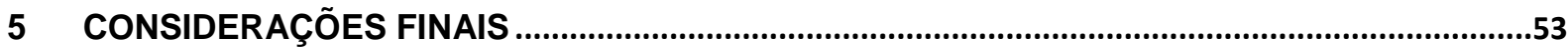

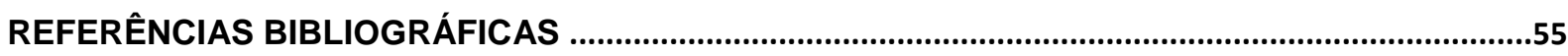

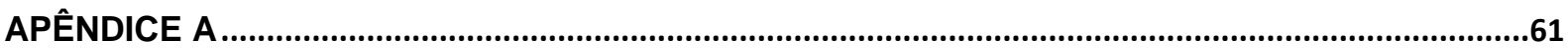

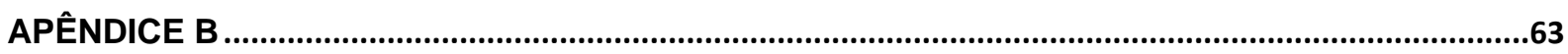


APÊNDICE C..

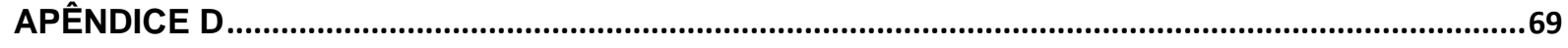

ANEXO 


\section{Capítulo 1}

\section{Introdução}

A obesidade é um problema de saúde pública mundial, caracterizada pelo excesso de tecido adiposo e Índice de Massa Corporal (IMC) $\geq 30 \mathrm{~kg} / \mathrm{m}^{2}$ é reconhecida como uma doença epidêmica e multifatorial. ${ }^{1,2}$

Nesse contexto, a Organização Mundial de Saúde (OMS) informa que no mundo existem 650 milhões de adultos (>18 anos) obesos, sendo que 1,9 bilhões já apresentam sobrepeso (IMC $\left.\geq 25<30 \mathrm{~kg} / \mathrm{m}^{2}\right)^{3}$. Contudo, a problemática poderá se agravar no futuro, pois se estima que em 2025 existirão 2,3 bilhões de adultos com sobrepeso e mais de 700 milhões com obesidade 4 .

No Brasil, a prevalência de obesidade e sobrepeso entre 20 e 59 anos de idade, aumentou entre os anos 1975 e 2009; a obesidade passou de 2,8 para 12,4\% nos homens e de 8,0 para $16,9 \%$ nas mulheres, enquanto que o sobrepeso, aumentou de 18,5 para $50,1 \%$ e de 28,7 para $48 \%$, respectivamente em homens e mulheres. ${ }^{5,6} \mathrm{~A}$ frequência da obesidade está crescendo rapidamente, como mostram dados encontrados na pesquisa de Vigilância de Fatores de Risco e Proteção para Doenças Crônicas por Inquérito Telefônico (Vigitel), que em dez anos (2006-2016) passou de 11,8 para $18,9 \%$, sendo que, uma em cada cinco pessoas estão acima do peso no Brasil?.

Em ambos os sexos, o aumento de peso é notável, mas as mulheres têm maior propensão ao excesso de peso quando comparadas aos homens, pois seu ganho de peso frequentemente está associado a efeitos adversos à saúde na fase reprodutiva, diminuição da fertilidade e aumento da probabilidade de doenças crônicas, como diabetes e hipertensão, na gestação. ${ }^{8}$

No mundo, atualmente 2,8 milhões de pessoas morrem anualmente em decorrência de complicações causadas pelo excesso de peso. ${ }^{9,10}$ 
O excesso de peso pode estar contribuindo para o surgimento de diversas doenças na população mundial. As chamadas Doenças Crônicas Não Transmissíveis (DCNT), como hipertensão arterial, dislipidemia, diabetes tipo 2 , doenças cardiovasculares dentre outras, estão associadas ou surgem em decorrência do sobrepeso e da obesidade. ${ }^{11}$

O aumento da prevalência do excesso de peso está relacionado a mudanças no estilo de vida da população. Essas alterações constituem um fator de risco modificável para as DCNT, que representam um alto custo para o sistema de saúde pública em função de suas complicações que trazem como consequência o aumento de incapacitações, de hospitalizações e da mortalidade. ${ }^{12}$

O uso de tabaco, consumo excessivo de álcool, alimentação inadequada e inatividade física, são condições modificáveis e relevantes na redução da morbidade e mortalidade causada pelo excesso de peso. ${ }^{13}$ Nesse sentido, percebe-se que hábitos benéficos à saúde (não fumar, consumir frutas e hortaliças diariamente, praticar atividade física regularmente, dentre outros), não são comuns no cotidiano da maioria da população adulta, aumentando a probabilidade de DCNT. ${ }^{14,15}$

A recomendação de atividade física preconizada pela Organização Mundial de Saúde é de 150 minutos por semana de atividade moderada, para população acima de 18 anos $^{16}$. Baixos níveis de atividade física têm sido associados ao aumento do risco cardiometabólico global e também ao excesso de peso, ${ }^{17}$ e consequentemente à elevação da morbimortalidade por doenças crônicas, tais como, hipertensão, diabetes, cardiopatias e doenças cerebrovasculares. . $^{2,18,19,20}$

É notório em estudos prévios que a inatividade física nas horas de lazer contribui para o avanço das DCNT 16,18,19. Estudar a população confirmando essa realidade, contribui para que haja planos de promoção da saúde e intervenções por órgãos responsáveis, sendo assim, o Ministério da Saúde, na busca por melhorias, implementou a Academia de Saúde para práticas de atividade física monitorada, ${ }^{23}$ apoiando assim as ações desenvolvidas na atenção básica, principalmente pela Estratégia de Saúde da Família (ESF) ${ }^{21}$, que é caracterizada por visita domiciliar realizada por agentes comunitários de saúde e cuidado integrado do usuário pela equipe. Em alguns municípios, a ESF pode contar com o auxílio do Núcleo de Apoio a Saúde da Família (NASF)22, composto por uma equipe multidisciplinar com fisioterapeuta, nutricionista, psicólogo, educador físico, entre outros, que contribuem matriciando (construção compartilhada; intervenção pedagógica- terapêutica) as 
equipes sobre assuntos pré-determinados na tentativa de minimizar morbidades e mortalidades.

Além da inatividade física, os hábitos alimentares são marcadores de risco para doenças, na medida em que o consumo elevado de colesterol, lipídeos e ácidos graxos saturados, somado ao baixo consumo de fibras, participam no desenvolvimento de doenças cardiovasculares, dislipidemias, obesidade, diabetes e hipertensão. ${ }^{24,25}$

Por outro lado, alguns fatores podem restringir os hábitos alimentares mais saudáveis, tais como, a exclusão social, a baixa escolaridade, a renda escassa e a falta ou má qualidade de informações disponíveis, que dificultam o planejamento de uma alimentação diversificada, com procedência segura e conhecida. ${ }^{26} \mathrm{O}$ crescimento e desenvolvimento urbano, podem ter contribuído para aumento de peso e consequentemente de DCNT, contribuindo para troca de carboidratos complexos e fibras por alimentos ricos em gordura e açúcares, devido à maior acessibilidade e praticidade. ${ }^{27}$

No ano de 2006 foi lançado pelo Ministério da Saúde, o primeiro Guia Alimentar para a população brasileira, com orientações adequadas para prevenção de doenças crônicas não transmissíveis, como obesidade, diabetes, hipertensão, entre outras. ${ }^{28}$

As DCNT vêm crescendo continuamente no Brasil e no mundo, onde políticas públicas são executadas como forma de minimizar os agravos em todas as faixas etárias, o Guia alimentar é um exemplo de estratégia para auxiliar a população brasileira com orientações sobre hábitos alimentares saudáveis.

O Brasil e outros países seguem recomendações da OMS, que é responsável por propagar no mundo políticas de promoção da saúde, possui como principal objetivo reduzir mortes e doenças, através de ações em saúde pública e medidas preventivas que diminuam os fatores de risco para doenças crônicas, preconizada na atenção primária, a fim de promover uma comunidade mais saudável. ${ }^{29}$

A reunião da OMS realizada em 2015, propôs ações para minimizar maus hábitos alimentares da população, como aumentar impostos sobre bebidas açucaradas (refrigerantes e sucos industrializados) e oferecer subsídios para diminuir de 10 a $30 \%$ os preços de frutas, verduras e legumes, melhorando assim o acesso da população com menor poder aquisitivo. ${ }^{30}$

O Brasil seguindo o proposto pela OMS, estabeleceu três metas importantes para atingir até 2019: a redução de 30\% do consumo de bebidas açucaradas, como o 
refrigerante e suco artificial, aumentar o consumo de frutas, verduras e legumes em pelo menos $17,8 \%$ e conter o avanço da obesidade, através de segurança alimentar nutricional e políticas intersetoriais de saúde. ${ }^{31}$

Com o panorama geral da obesidade no mundo há necessidade de se conhecer os hábitos alimentares e estilos de vida adotados pela população, na tentativa de elaborar planos de ação em busca de melhorias a partir dos resultados obtidos. Sendo assim, o Instituto Brasileiro de Geografia e Estatística (IBGE), em conjunto com o Ministério da Saúde, realizaram a Pesquisa Nacional de Saúde (PNS) ${ }^{32}$, no ano de 2013. A pesquisa teve o intuito de conhecer as condições de saúde da população brasileira e fatores de risco associados, para formular, avaliar e monitorar as políticas públicas e atingir uma maior efetividade e eficácia nas ações governamentais ${ }^{33}$.

O município de estudo também traz o reflexo desse contexto nacional/mundial do excesso de peso. Confirmar essa realidade é de suma importância para possíveis intervenções minimizando agravos na saúde da população. A ESF é escolhida como local de pesquisa devido ao maior vínculo com o usuário, facilitando futuras atuações da gestão na busca por melhoria da saúde do município.

Desse modo, esse tema requer pesquisas e produções científicas que abordem o estilo de vida, o estado nutricional, nível de escolaridade e classificação econômica, para contribuir com novas políticas públicas e ações em saúde municipais que visam à diminuição de morbidade e mortalidade da população em decorrência da obesidade e estilo de vida inadequado.

\subsection{Objetivos}

Avaliar o estado nutricional e identificar o estilo de vida de indivíduos adultos e idosos, usuários das Estratégias de Saúde da Família (ESF) do município de Bebedouro. 


\subsubsection{Objetivos Específicos}

- Avaliar o estado nutricional de acordo com IMC na população maior de 20 anos usuárias das ESFs.

- Caracterizar os usuários das ESFs quanto à escolaridade, condição econômica e hábito alimentar.

- Estimar a frequência de tabagismo e consumo de álcool.

- Estimar a frequência de atividade física e horas de sono. 



\section{Capítulo 2}

\section{Casuística e Métodos}

\subsection{Delineamento do Estudo}

Trata-se de um estudo descritivo, do tipo inquérito, com entrevistas individualizadas e emprego de questionário aplicado pelo pesquisador.

\subsection{Contexto}

\subsubsection{Local}

Este estudo foi realizado no município de Bebedouro/SP, localizado na região norte do estado de São Paulo, com aproximadamente 77 mil habitantes ${ }^{34}$, composto por onze Estratégias de Saúde da Família e cinco Unidades Básicas de Saúde. O município pesquisado tinha uma cobertura de atendimento das ESFs até 2015 de 47\% da população; com as novas reestruturações da gestão municipal, a taxa de cobertura passou a ser em 2018 de $63 \%$.

\subsubsection{Recrutamento}

O período de recrutamento dos participantes foi de oito meses (outubro de 2016 a maio de 2017), nas onze ESFs de Bebedouro. Foram convidados a participar do estudo, os indivíduos adultos ( $\geq 20$ anos de idade) que estavam presentes no dia da 
visita à unidade. Após serem informados de que se tratava de uma pesquisa e esclarecidos sobre os procedimentos, assinavam o termo de consentimento livre e esclarecido - TCLE, caso concordassem em participar.

\subsection{Participantes}

Cada ESF possui aproximadamente 2500 pessoas cadastradas, sendo que procuram o serviço diariamente, em média 20 pessoas.

Os critérios de inclusão para o estudo foram:

- Estar cadastrado na ESF

- Possuir mais de 20 anos de idade

- Aceitar participar da pesquisa

Os critérios de exclusão para o estudo foram:

- Estar grávida

- Ter dificuldade para subir na balança

- Estar em fase aguda de qualquer condição clínica

- Ter necessidade especial

O critério de escolha por maiores de 20 anos foi estabelecido devido aos registros do Sistema de Informação da Atenção Básica (SIAB) de 2015 que divide a faixa etária em 20 a 39 anos, 40 a 49 anos, 50 a 59 anos e 60 anos ou mais.

\subsection{Variáveis}

\subsubsection{Variáveis de interesse}

I - Dados sociodemográficos e econômicos.

- Idade (anos completos)

- Sexo

- Estado civil

- Escolaridade 
- Classe Econômica

II - Características/Informações pessoais e de saúde.

- Peso

- Altura

- Índice de Massa Corporal - IMC

- Uso de álcool e cigarro

- Hábitos alimentares

- Prática de atividade física

- Horas de sono

- Classificação de saúde

\subsection{Coleta de dados}

O estudo foi autorizado pelo Diretor Municipal de Saúde da cidade de Bebedouro-SP e aprovado pelo Comitê de Ética e Pesquisa do Centro de Saúde Escola da Faculdade de Medicina de Ribeirão Preto da Universidade de São Paulo (CAAE:75509317.5.0000.5414). Os indivíduos que aceitaram participar da pesquisa, após assinarem o Termo de Consentimento Livre e Esclarecido (TCLE), eram encaminhados para aferir o peso e a altura, na balança digital da ESF pesquisada, de marca Micheletti, com capacidade de $200 \mathrm{~kg}$. Feito isso, cada participante respondeu ao pesquisador questões sobre aspectos sociodemográficos, econômicos e sobre estilo de vida (módulo P da Pesquisa Nacional de Saúde-PNS de 2013, adaptado). ${ }^{32}$ Para classificação socioeconômica, o questionário foi baseado no da Associação Brasileira de Empresas de Pesquisa (ABEP). ${ }^{35}$ Os questionários foram processados através do Epilnfo versão 7.2, que é um software criado pelo Centers for Disease Control and Prevention (CDC). Foi utilizado um computador portátil na realização da entrevista, para registrar as informações. O estado nutricional dos participantes foi classificado seguindo as recomendações do Ministério da Saúde, que apresentam diferentes pontos de corte para o IMC, para adultos e idosos ${ }^{36}$. Os adultos foram classificados em baixo peso (IMC $<18,5 \mathrm{~kg} / \mathrm{m}^{2}$ ), eutrófico (IMC $\geq 18,5 \mathrm{e}<25$ $\mathrm{kg} / \mathrm{m}^{2}$ ), sobrepeso (IMC $\geq 25$ e $<30 \mathrm{~kg} / \mathrm{m}^{2}$ ) e obeso (IMC $\geq 30 \mathrm{~kg} / \mathrm{m}^{2}$ ); os idosos em 
baixo peso (IMC $\left.\leq 22 \mathrm{~kg} / \mathrm{m}^{2}\right)$, eutrófico $\left(\mathrm{IMC}>22\right.$ e $\left.<27 \mathrm{~kg} / \mathrm{m}^{2}\right)$ e sobrepeso $(\mathrm{IMC} \geq$ $\left.27 \mathrm{~kg} / \mathrm{m}^{2}\right)$.

\subsection{Fonte de Dados}

- Questionário sociodemográfico e econômico (ABEP) está apresentado no Apêndice A: Este instrumento avaliou as seguintes variáveis de interesse: (I) idade do participante, em anos completos; (II) sexo: masculino ou feminino; (III) estado civil: solteiro(a), casado(a) no civil, união estável, separado(a) ou viúvo(a); (IV) escolaridade: analfabeto/ fundamental I incompleto; ensino fundamental I/ fundamental II incompleto, ensino fundamental $\mathrm{II} /$ médio incompleto, ensino médio/superior incompleto, ensino superior completo; (V) posse de itens: banheiro, empregada mensalista, automóvel, computador, lava louça, geladeira, freezer, máquina de lavar roupa, dvd, micro-ondas, motocicleta, secadora de roupa

- Questionário da Pesquisa Nacional de Saúde (PNS) - módulo P - Estilo de Vida, está apresentado no Apêndice B. Contempla os seguintes itens: (I) hábitos alimentares: frequência semanal de consumo de frutas e hortaliças, consumo regular de feijão, consumo de carnes com excesso de gordura, consumo regular de refrigerante e/ou sucos artificiais, consumo de doces, consumo de sal; (II) prática de atividade física: prática do nível recomendado de atividade física no tempo livre, assistem televisão por três horas ou mais por dia; (III) consumo de álcool: frequência do consumo de bebida alcoólica; (IV) tabagismo: percentuais de fumantes e ex-fumantes. Foram acrescentadas no questionário seis variáveis: (a) peso em kg; (b) altura em metros; (c) IMC em kg/m², (d) consumo de água; (e) horas de sono; (f) autoclassificação de saúde. 


\subsection{Tamanho Amostral}

\subsubsection{Cálculo Amostral}

Com base na estimativa da proporção populacional, tem se a formula abaixo para encontrar o tamanho amostral.

$$
n=\frac{N \times \hat{p} \times \hat{q} \times(Z \alpha / 2)^{2}}{\widehat{p} \times \hat{q} \times(Z \alpha / 2)^{2}+(N-1) \times E^{2}}
$$

Eq. 1

O tamanho amostral encontrado é um total de 378 pessoas, considerando que $\mathrm{N}=23314, \hat{p}=80 \%, \hat{q}=20 \%, Z \alpha / 2=95 \%$ e $E=4 \%$, sendo estratificado para cada Estratégia de Saúde da Família, conforme a tabela abaixo.

Tabela 1 - Unidades de ESF de Bebedouro estratificadas por número de usuários, para cálculo do tamanho da amostra.

\begin{tabular}{lccc}
\hline ESF & \multicolumn{3}{c}{ \% POR } \\
TOTAL N & ESF & TOTAL n \\
\hline ESF 1 & 1950 & 8,36 & 32 \\
ESF 2 & 1821 & 7,81 & 30 \\
ESF 3 & 2383 & 10,22 & 39 \\
ESF 4 & 2160 & 9,26 & 35 \\
ESF 5 & 2303 & 9,88 & 37 \\
ESF 6 & 2301 & 9,87 & 37 \\
ESF 7 & 2499 & 10,72 & 41 \\
ESF 8 & 2237 & 9,59 & 36 \\
ESF 9 & 2180 & 9,35 & 35 \\
ESF 10 & 2266 & 9,72 & 37 \\
ESF 11 & 1214 & 5,21 & 20 \\
\hline TOTAL & 23314 & 100 & 378 \\
\hline
\end{tabular}




\subsubsection{Seleção}

Os participantes foram selecionados por conveniência, ou seja, aqueles que estavam presentes na ESF no dia da coleta, que aceitaram a participar e assinaram o termo de consentimento, até completar a cota amostral da unidade. Não houve recusas, todas as pessoas que o pesquisador conseguiu abordar aceitaram participar. O questionário foi aplicado enquanto os participantes aguardavam por atendimento médico ou procedimento de enfermagem.

\subsection{Método Estatístico}

A análise descritiva das variáveis foi resumida, com frequências relativas e absolutas. Para comparar a frequência do consumo alimentar entre as classificações nutricionais e entre os grupos de adultos e idosos, foi utilizado um modelo de regressão adotando a distribuição beta-binomial, através de técnicas Bayesianas com o auxílio do software Open Bugs ${ }^{37}$. Este método considera o consumo semanal dos alimentos variando de 0 a 7 e o consumo diária de água variando de 0 a 13 . Os Softwares para análise foram $\mathrm{R}^{38}$ e Open Bugs ${ }^{37}$.

O intervalo de credibilidade de 95\% (análogos aos intervalos de confiança 95\%) apresentou as diferenças estimadas. Os intervalos que não englobavam o valor zero, trouxeram evidências de diferença entre os grupos e seus limites inferior e superior mostram a diferença desta magnitude; os que passavam pelo zero não apresentavam evidências de diferenças.

Para analisar as variáveis categóricas (gordura da carne e pele do frango), utilizou-se o teste do qui-quadrado e o teste exato de Fisher quando as suposições do qui-quadrado não são satisfeitas. Foi verificada a existência de associação dos grupos adulto e idoso com a classificação nutricional (baixo peso, eutrófico, sobrepeso e obeso para adultos e baixo peso, eutrófico e sobrepeso para idosos). 


\section{Capítulo 3}

\section{Resultados}

\subsection{Caracterização da Amostra}

A distribuição da população estudada de acordo com faixa etária, sexo, estado civil e escolaridade está apresentada na Tabela 2. A média e desvio padrão da idade foi de 47,8 anos $( \pm 14,6)$. A faixa etária mais frequente foi a de 20 -39 anos (33,9\%), seguida pelas faixas etárias de 50 - 59 anos $(25,4 \%)$ e maior que 60 anos (22\%); a menos frequente foi a de 40 - 49 anos (18,6\%).

Observou-se predominância do sexo feminino $(74,5 \%)$ em relação ao masculino $(25,5 \%)$.

Em relação ao estado civil, a maioria é de casados (50,9\%), seguida por solteiros (17,8\%), união estável (12,9\%), divorciados (12,9\%) e viúvos (5,5\%).

Quanto à escolaridade, percebe-se uma predominância da categoria ensino médio completo/superior incompleto $(38,6 \%)$, seguida pelas categorias ensino fundamental I completo/ensino fundamental II incompleto (24,7\%), analfabeto/fundamental I incompleto (17\%), ensino fundamental II completo/ensino médio incompleto (12,9\%) e ensino superior completo $(6,8 \%)$.

Portanto, a população estudada é predominantemente da faixa etária de 20 a 39 anos, do sexo feminino, casada e com ensino médio completo/superior incompleto. 
Tabela 2 - Distribuição da população estudada, de acordo com faixa etária, sexo, estado civil e escolaridade. Bebedouro, 2017.

\begin{tabular}{llcc}
\hline & & $\begin{array}{c}\text { Frequência } \\
\text { Relativa }\end{array}$ & $\begin{array}{c}\text { Frequência } \\
\text { Absoluta }\end{array}$ \\
\hline $\begin{array}{l}\text { Faixa Etária } \\
\text { (anos) }\end{array}$ & 20 a 39 & $33,9 \%$ & \\
& 40 a 49 & $18,6 \%$ & 129 \\
& 50 a 59 & $25,4 \%$ & 71 \\
& 60 ou + & $22,1 \%$ & 97 \\
\hline Total & & $100 \%$ & 84 \\
\hline Sexo & Masculino & $25,5 \%$ & 381 \\
& Feminino & $74,5 \%$ & 97 \\
\hline Total & & $100,0 \%$ & 384 \\
\hline Estado Civil & Solteiro & $17,7 \%$ & 68 \\
& Casado & $50,9 \%$ & 194 \\
& União Estável & $12,9 \%$ & 49 \\
& Divorciado & $12,9 \%$ & 49 \\
& Viúvo & $5,5 \%$ & 21 \\
\hline Total & & $100,0 \%$ & 381 \\
\hline \multirow{2}{*}{ Escolaridade } & Analfabeto/Fundamental 1 & $17,1 \%$ & 65 \\
& incompleto & & \\
& Fundamental 1 completo/2 & $24,7 \%$ & 94 \\
& incompleto & $12,9 \%$ & 49 \\
& Fundamental 2 & & \\
& completo/Médio incompleto & $38,6 \%$ & 147 \\
& Médio completo/Superior & $6,8 \%$ & 26 \\
\hline incompleto & $100 \%$ & 381 \\
\hline TOTAL & Superior Completo & &
\end{tabular}

\subsection{Classificação Socioeconômica}

Para a classificação socioeconômica foram utilizados os seguintes pontos de corte:

$0-16$ pontos: classe $\mathrm{D}-\mathrm{E}$;

17-22 pontos: classe $\mathrm{C} 2$;

23-28 pontos: classe $\mathrm{C} 1$;

29-37 pontos: classe B2; 
38-44 pontos: classe $B 1 \mathrm{e}$

45-100 pontos: classe A.

Neste estudo, a classe socioeconômica mais frequente foi a D-E $(59,5 \%)$, seguida por C2 $(25,9 \%)$, C1 $(11,3 \%)$ e B2 $(3,3 \%)$; não houve representações nas classes B1 e A.

\subsection{Hábitos Gerais e Estilo de Vida}

\subsubsection{Padrão de Sono}

Em relação ao padrão de sono, foi questionado quantas horas ininterruptas por dia cada indivíduo possuía de sono. Foi observado que a maioria dos entrevistados não chegava a apresentar 6 horas de sono, sendo, 158 pessoas $(41,5 \%)$ que dormiam de 1 a 4 horas por dia, 122 pessoas (32\%) de 4 a 6 horas, 87 pessoas (22,8\%) de 6 a 8 horas, e 14 pessoas $(3,7 \%)$ mais de 8 horas.

\subsubsection{Atividade Física}

A prática de atividade física foi questionada em relação a três categorias: dias por semana praticados, tipos de atividade física e horas praticadas por dia. Em relação aos dias por semana praticados, 255 pessoas $(66,9 \%)$ não praticam nenhum dia de atividade física, 8 pessoas $(2,1 \%)$ praticam um dia da semana, 30 pessoas $(7,9 \%)$ praticam dois dias da semana, 20 pessoas $(5,3 \%)$ praticam três dias da semana, 11 pessoas $(2,9 \%)$ praticam quatro vezes na semana, 36 pessoas $(9,5 \%)$ praticam cinco vezes na semana, 8 pessoas (2\%) praticam seis vezes na semana, 13 pessoas $(3,4 \%)$ praticam todos os dias da semana.

Referente a carga horária praticada, por aqueles que citaram praticar atividade física, 24 pessoas $(6,3 \%)$ praticam de quinze a trinta minutos, 77 pessoas $(20,2 \%)$ de trinta a sessenta minutos, 19 pessoas $(5 \%)$ de sessenta a noventa minutos e 6 pessoas $(1,6 \%)$ de noventa a cento e vinte minutos. 
A modalidade de atividade física mais praticada é a caminhada, com 68 pessoas $(17,6 \%)$, seguida por ginastica aeróbica com 35 pessoas $(9,2 \%)$, hidroginástica com 10 pessoas $(2,6 \%)$, musculação com 7 pessoas $(1,8 \%)$ e outras modalidades com 6 pessoas $(1,6 \%)$.

Também foi questionado aos entrevistados se consideravam que nas proximidades de seu domicilio havia algum local público para prática de atividade física, sendo que 236 pessoas $(61,9 \%)$ referiram que sim e 145 pessoas $(38,1 \%)$ referiram que não.

De modo geral entre os praticantes de atividade física, predomina a prática de caminhada, frequência de cinco vezes na semana, duração de trinta a sessenta minutos de atividade e de pessoas que conhecem locais públicos para práticas de atividade.

\subsubsection{Horas em frente à televisão}

Foi avaliado o tempo em que as pessoas passavam em frente à televisão (TV). A maior frequência foi de três horas em frente à TV, por 112 pessoas $(29,4 \%)$, seguido pelas categorias, mais de quatro horas por 96 pessoas $(25,2 \%)$, de uma a duas horas por 76 pessoas $(20 \%)$, menos de uma hora por 76 pessoas $(20 \%)$ e 21 pessoas $(5,4 \%)$ referiram não assistir TV.

\subsubsection{Consumo de Álcool}

Em relação ao consumo de álcool, 228 pessoas (59,8\%) referiram não consumir, 47 pessoas $(12,3 \%)$ referiram o consumo menor que uma vez por mês e 106 pessoas $(27,9 \%)$ referiram o consumo de uma vez ou mais por mês.

Dentre os que consomem álcool uma vez ou mais por mês, 39 pessoas (10,3\%) consomem uma vez na semana, 27 pessoas $(7,1 \%)$ consomem duas vezes na semana, 19 pessoas $(5 \%)$ consomem três vezes na semana, 8 pessoas $(2,1 \%)$ consomem quatro vezes na semana, 2 pessoas $(0,5 \%)$ consomem cinco vezes na semana, 1 pessoa $(0,3 \%)$ consome seis vezes na semana e 10 pessoas $(2,6 \%)$ consomem diariamente. 


\subsubsection{Tabagismo}

Para o hábito de fumar foram investigadas três situações: quem é tabagista, quantidade de cigarros por dia e se já foi tabagista.

A população estudada, apresentou uma frequência elevada de não fumantes, que corresponde a 321 pessoas $(84,2 \%)$. O hábito de fumar diariamente foi mencionado por 57 pessoas (15\%) e o hábito de fumar menos que uma vez no dia por 3 pessoas $(0,8 \%)$. Em relação à quantidade de cigarros fumados, a maioria fuma três ou mais cigarros por dia o equivalente a 56 pessoas $(14,7 \%)$ e 4 pessoas $(1,1 \%)$ fumam entre um cigarro por dia ou menos que um cigarro por semana.

Os entrevistados ao serem questionados se já foram tabagistas, 249 pessoas $(65,3 \%)$ referiram que nunca fizeram uso do tabaco, 129 pessoas $(33,9 \%)$ referiram que fumavam diariamente e 3 pessoas $(0,8 \%)$ referiram que fumavam menos que uma vez ao dia.

\subsubsection{Auto Avaliação de Saúde}

Os participantes foram questionados sobre sua percepção em relação a sua própria saúde e Ihes foram dadas as seguintes opções de resposta: muito bom, bom, regular, ruim e muito ruim.

A maior parte dos estudados, 181 pessoas (47,5\%), se auto classificaram como bom, seguido pela classificação regular referida por 137 pessoas (36\%), ruim referida por 35 pessoas $(9,2 \%)$, muito bom referida por 19 pessoas $(5 \%)$ e por último muito ruim referida por 9 pessoas $(2,3 \%)$.

\subsubsection{Percepção do Consumo de Sal}

Em relação ao sal, foi avaliada a auto percepção de cada participante do estudo, sobre o hábito de consumo de alimentos salgados com sal de cozinha e alimentos industrializados. Haviam cinco possibilidades de respostas para o consumo: muito alto, alto, adequado, muito baixo e baixo.

A prevalência mais elevada sobre a auto percepção do consumo de sal correspondeu a 167 pessoas $(43,8 \%)$ que consideraram seu consumo adequado, seguido por, 143 pessoas $(37,5 \%)$ que consideraram seu consumo baixo. A auto 
percepção de consumo alto ou muito alto foi referido por 60 pessoas $(15,8 \%)$ e 6 pessoas $(1,6 \%)$ respectivamente. A auto percepção de consumo muito baixa foi referida por 5 pessoas $(1,3 \%)$.

\subsection{Consumo Alimentar e Ingestão Hídrica}

Os dados referentes ao consumo alimentar, expressos pelo número de vezes que o indivíduo ingere cada grupo de alimento durante uma semana, podem ser encontrados em síntese na Tabela 3.

Tabela 3 - Frequência do Consumo Alimentar, por número de dias da semana, na população adulta que utiliza a ESF de Bebedouro, SP - 2017.

\begin{tabular}{|c|c|c|c|c|c|c|c|c|c|c|}
\hline Dias por & semana & 0 & 1 & 2 & 3 & 4 & 5 & 6 & 7 & Total \\
\hline \multirow{2}{*}{ Feijão } & $\begin{array}{c}\text { Frequência } \\
\text { Relativa }\end{array}$ & 10,0 & 6,0 & 7,1 & 6,8 & 4,2 & 14,2 & 18,1 & 33,6 & 100 \\
\hline & $\begin{array}{c}\text { Frequência } \\
\text { Absoluta }\end{array}$ & 38 & 23 & 27 & 26 & 16 & 54 & 69 & 128 & 381 \\
\hline \multirow{2}{*}{$\begin{array}{l}\text { Hortaliças } \\
\text { Cruas }\end{array}$} & $\begin{array}{c}\text { Frequência } \\
\text { Relativa }\end{array}$ & 10,3 & 5,5 & 11,6 & 19,8 & 7,1 & 9,0 & 6,6 & 30,1 & 100 \\
\hline & $\begin{array}{c}\text { Frequência } \\
\text { Absoluta }\end{array}$ & 39 & 21 & 44 & 75 & 27 & 34 & 25 & 116 & 381 \\
\hline \multirow{2}{*}{$\begin{array}{l}\text { Hortaliças } \\
\text { Cozidas }\end{array}$} & $\begin{array}{c}\text { Frequência } \\
\text { Relativa }\end{array}$ & 12,9 & 8,4 & 12,6 & 21,3 & 6,6 & 11,0 & 4,5 & 22,8 & 100 \\
\hline & $\begin{array}{c}\text { Frequência } \\
\text { Absoluta }\end{array}$ & 49 & 32 & 48 & 81 & 25 & 42 & 17 & 87 & 381 \\
\hline \multirow{2}{*}{$\begin{array}{l}\text { Carne Boi e } \\
\text { Porco }\end{array}$} & $\begin{array}{c}\text { Frequência } \\
\text { Relativa }\end{array}$ & 7,4 & 9,7 & 17,9 & 23,6 & 21,3 & 10,2 & 3,4 & 6,6 & 100 \\
\hline & $\begin{array}{c}\text { Frequência } \\
\text { Absoluta }\end{array}$ & 28 & 37 & 68 & 90 & 81 & 39 & 13 & 25 & 381 \\
\hline \multirow{2}{*}{ Frango } & $\begin{array}{c}\text { Frequência } \\
\text { Relativa }\end{array}$ & 6,3 & 14,4 & 23,9 & 30,7 & 12,9 & 5,2 & 4,2 & 2,4 & 100 \\
\hline & $\begin{array}{c}\text { Frequência } \\
\text { Absoluta }\end{array}$ & 24 & 55 & 91 & 117 & 49 & 20 & 16 & 9 & 381 \\
\hline \multirow{2}{*}{ Peixe } & $\begin{array}{c}\text { Frequência } \\
\text { Relativa }\end{array}$ & 81,4 & 13,4 & 3,9 & 0,5 & 0,5 & 0,3 & 0 & 0 & 100 \\
\hline & $\begin{array}{c}\text { Frequência } \\
\text { Absoluta }\end{array}$ & 310 & 51 & 15 & 2 & 2 & 1 & 0 & 0 & 381 \\
\hline \multirow{2}{*}{ Leite } & $\begin{array}{c}\text { Frequência } \\
\text { Relativa }\end{array}$ & 35,0 & 3,9 & 3,9 & 4,5 & 2,9 & 1,6 & 0,8 & 47,4 & 100 \\
\hline & $\begin{array}{c}\text { Frequência } \\
\text { Absoluta }\end{array}$ & 133 & 15 & 15 & 17 & 11 & 6 & 3 & 181 & 381 \\
\hline \multirow{2}{*}{ Fruta } & $\begin{array}{c}\text { Frequência } \\
\text { Relativa }\end{array}$ & 21,6 & 10,3 & 10,8 & 11,6 & 5,5 & 8,7 & 2,6 & 29 & 100 \\
\hline & $\begin{array}{c}\text { Frequência } \\
\text { Absoluta }\end{array}$ & 82 & 39 & 41 & 44 & 21 & 33 & 10 & 111 & 381 \\
\hline
\end{tabular}




\begin{tabular}{|c|c|c|c|c|c|c|c|c|c|c|}
\hline \multicolumn{2}{|c|}{ Dias por semana } & 0 & 1 & 2 & 3 & 4 & 5 & 6 & 7 & Total \\
\hline \multirow{2}{*}{ Suco de Fruta } & $\begin{array}{c}\text { Frequência } \\
\text { Relativa }\end{array}$ & 56,1 & 6,3 & 11,6 & 7,6 & 2,6 & 5,5 & 0,3 & 10,0 & 100 \\
\hline & $\begin{array}{c}\text { Frequência } \\
\text { Absoluta }\end{array}$ & 214 & 24 & 44 & 29 & 10 & 21 & 1 & 38 & 381 \\
\hline \multirow{2}{*}{$\begin{array}{l}\text { Refrigerante e } \\
\text { Suco } \\
\text { Industrializado }\end{array}$} & $\begin{array}{l}\text { Frequência } \\
\text { Relativa }\end{array}$ & 28,2 & 11,3 & 10,5 & 10,8 & 3,7 & 1,8 & 0,5 & 33,2 & 100 \\
\hline & $\begin{array}{c}\text { Frequência } \\
\text { Absoluta }\end{array}$ & 107 & 43 & 40 & 41 & 14 & 7 & 2 & 127 & 381 \\
\hline \multirow{2}{*}{ Doces } & $\begin{array}{l}\text { Frequência } \\
\text { Relativa }\end{array}$ & 40,0 & 10,00 & 10,5 & 6,8 & 3,9 & 4,7 & 0,7 & 23,4 & 100 \\
\hline & $\begin{array}{c}\text { Frequência } \\
\text { Absoluta }\end{array}$ & 152 & 38 & 40 & 26 & 15 & 18 & 3 & 89 & 381 \\
\hline \multirow{2}{*}{ Fast Food } & $\begin{array}{l}\text { Frequência } \\
\text { Relativa }\end{array}$ & 55,1 & 20,00 & 13,4 & 6,3 & 2,6 & 1,3 & 1,3 & 0 & 100 \\
\hline & $\begin{array}{c}\text { Frequência } \\
\text { Absoluta }\end{array}$ & 210 & 76 & 51 & 24 & 10 & 5 & 5 & 0 & 381 \\
\hline
\end{tabular}

\subsubsection{Consumo Alimentar}

Os participantes foram questionados sobre quantos dias por semana consumiam alimentos de treze grupos alimentares: feijão, hortaliças cruas, hortaliças cozidas, carne bovina e suína, frango, gordura aparente de carne e pele de frango, peixe, leite, frutas, suco de fruta, refrigerante e suco industrializado, doces e fast-food. Além das análises de frequência para o grupo de ingestão alimentar, também foram realizadas comparações utilizando um modelo de regressão. As frequências do consumo alimentar foram comparadas entre os grupos adultos e idosos e entre as diferentes classificações do estado nutricional. Para as variáveis categóricas foram utilizados o teste qui-quadrado e teste exato de Fisher.

Em relação ao consumo de feijão, percebe-se que a maioria das pessoas (128 indivíduos ou $33,6 \%$ ), ingere o alimento sete dias por semana, seguido por seis dias por semana (69 pessoas ou 18,1\%); cinco dias por semana (54 pessoas ou $14,2 \%$ ); nenhum dia na semana (38 pessoas ou 10\%); dois dias por semana (27 pessoas ou $7,1 \%$ ); três dias por semana ( 26 pessoas ou $6,8 \%$ ); um dia na semana (23 pessoas ou $6 \%$ ) e quatro dias por semana (16 pessoas ou $4,2 \%$ ). Na análise de regressão para o grupo do feijão encontrou-se diferença significativa entre o consumo de adultos e idosos (limite inferior - 0,59 e limite superior - 0,03) e também na comparação entre o estado nutricional de sobrepeso e obesidade (limite inferior 0,21 e limite superior 1,37). As demais classificações nutricionais não mostraram evidencia de diferença. 
Referente ao consumo de hortaliças cruas nota-se que a maioria dos indivíduos apresenta ingestão de sete dias por semana, o equivalente a 116 pessoas (30,4\%). A ingestão de seis dias por semana correspondeu a 25 pessoas $(6,5 \%)$; cinco dias por semana a 34 pessoas (8,9\%); quatro dias por semana a 27 pessoas $(7,1 \%)$; três dias por semana a 75 pessoas (19,7\%); dois dias por semana a 44 pessoas $(11,6 \%)$; um dia por semana a 21 pessoas $(5,5 \%)$ e nenhum dia na semana a 39 pessoas $(10,3 \%)$.

O consumo de hortaliças cozidas, também foi mais expressivo em sete dias por semana, com 87 pessoas (22,8\%), seguido por, três dias por semana (81 pessoas ou $21,3 \%$ ); nenhum dia da semana (49 pessoas ou $12,8 \%$ ); dois dias por semana (48 pessoas ou 12,6\%); cinco dias por semana (42 pessoas ou 11\%); um dia por semana (32 pessoas ou 8,4\%); quatro dias por semana (25 pessoas ou 6,6\%) e seis dias por semana (17 pessoas ou 4,5\%). Para este grupo de alimentos, a análise de regressão mostrou diferença significativa no consumo entre os grupos baixo peso e sobrepeso (limite inferior $-3,55$ e limite superior - 0,06) e entre o grupo baixo peso e obesidade (limite inferior - 3,71 e limite superior - 0,30).

O consumo de carnes foi separado em três tipos: carne bovina e suína, carne de frango e peixe e também foi questionado a retirada ou não da gordura aparente e pele do frango, como mostra na Tabela 4.

Tabela 4 - Frequência do Consumo de Gordura Aparente da Carne e Pele de Frango entre usuários adultos da ESF de Bebedouro, SP- 2017.

\begin{tabular}{lccc}
\hline & & $\begin{array}{c}\text { Frequência } \\
\text { Absoluta }\end{array}$ & $\begin{array}{c}\text { Frequência } \\
\text { Relativa }\end{array}$ \\
\hline $\begin{array}{l}\text { Gordura } \\
\text { Aparente }\end{array}$ & $\begin{array}{c}\text { Retira gordura } \\
\text { Não Retira } \\
\text { gordura }\end{array}$ & 230 & 60,4 \\
\hline Total & 151 & 39,6 \\
\hline $\begin{array}{l}\text { Pele de } \\
\text { Frango }\end{array}$ & $\begin{array}{c}\text { Retira pele } \\
\text { Nele }\end{array}$ & 381 & 100 \\
\hline Total & 252 & 66,40 \\
\hline
\end{tabular}

Em relação a carne bovina e suína, a maioria dos entrevistados referiu um consumo de três dias por semana (90 pessoas ou $23,6 \%$ ), seguido por quatro dias por semana ( 81 pessoas ou $21,3 \%$ ); dois dias por semana (68 pessoas ou $17,8 \%$ ); cinco 
dias por semana (39 pessoas ou 10,2\%); um dia por semana (37 pessoas ou 9,7\%); nenhum dia da semana (28 pessoas ou 7,3\%); sete dias por semana (25 pessoas ou $6,6 \%$ ) e seis dias por semana (13 pessoas ou 3,4\%). Ainda referente a carne bovina e suína, 230 pessoas $(60,4 \%)$ retiram a gordura aparente na hora do consumo, contra 151 pessoas $(39,6 \%)$ que não retiram a gordura na hora do consumo. Na análise de regressão houve diferença significativa no consumo entre adultos e idosos (limite inferior 0,03 e limite superior 0,88) e também entre os grupos eutrófico e obesidade (limite inferior 0,14 e limite superior1,33). Em relação a tirar ou não a gordura aparente da carne, observou-se uma diferença significativa entre os grupos adulto e idoso $(p=0,0076)$.

Referente a carne de frango, observou-se que a maioria dos indivíduos a consome três dias por semana (117 pessoas ou 30,7\%); dois dias por semana por 91 pessoas $(23,9 \%)$; uma vez por semana por 55 pessoas $(14,4 \%)$; quatro dias por semana por 49 pessoas (12,9\%); nenhum dia da semana por 24 pessoas (6,3\%); cinco dias da semana por 20 pessoas (5,2\%); seis dias por semana por 16 pessoas $(4,2 \%)$ e sete dias por semana por 9 pessoas (2,4\%). Ainda referente a carne de frango, verificou-se que 253 pessoas (66,4\%) retiram a pele na hora do consumo, em contrapartida, 128 pessoas (33,6\%) não retiram. Este grupo apresentou evidencia de diferença na análise de regressão ao se comparar o consumo entre eutróficos e obesos (limite inferior -1,30 e-0,35).

A maioria dos indivíduos referiram não comer peixe na semana (310 pessoas ou $81,4 \%)$, seguido por, 51 pessoas $(13,4 \%)$ que consomem um dia da semana; 15 pessoas (3,9\%) que consomem dois dias da semana; 2 pessoas (0,5\%) que consomem três dias da semana; 2 pessoas (0,5\%) que consomem quatro dias da semana e 1 pessoa (0,3\%) que consome cinco dias da semana.

O consumo diário de leite, ou seja, sete dias da semana foi referido 180 pessoas $(47,4 \%)$, mas também 133 pessoas (35\%) referiram não consumir leite nenhum dia da semana; 15 pessoas (3,9\%) ingerem um dia por semana; 15 pessoas (3,9\%) ingerem dois dias por semana; 18 pessoas (4,5\%) consomem três dias por semana; 11 pessoas (2,9\%) consomem quatro dias por semana; 6 pessoas $(1,6 \%)$ consomem cinco dias por semana e 3 pessoas $(0,8 \%)$ consomem seis dias por semana.

Em relação ao consumo de frutas, verificou-se que 110 pessoas $(28,8 \%)$ consomem todos os dias da semana; 10 pessoas $(2,6 \%)$ consomem seis dias por semana; 33 pessoas $(8,6 \%)$ consomem cinco dias por semana; 21 pessoas $(5,5 \%)$ 
consomem quatro dias da semana; 44 pessoas $(11,6 \%)$ consomem três dias por semana; 41 pessoas $(10,8 \%)$ consomem dois dias da semana; 39 pessoas $(10,3 \%)$ consomem uma vez por semana e 83 pessoas $(21,8 \%)$ não consomem frutas nenhum dia da semana. Também foi questionado o consumo de suco natural de fruta, que mostrou uma predominância de pessoas que não ingerem a bebida (214 pessoas ou $56,1 \%)$, seguido por 44 pessoas $(11,6 \%$ ) que consomem dois dias por semana; 38 pessoas (10\%) que consomem sete dias da semana; 29 pessoas $(7,6 \%)$ que consomem três dias por semana; 24 pessoas (6,3\%) que consomem um dia por semana; 21 pessoas (5,5\%) que consomem cinco dias por semana; 10 pessoas $(2,6 \%)$ que consomem quatro dias por semana e 1 pessoa $(0,3 \%)$ que consome seis dias da semana. De acordo com análise de regressão, houve diferença significativa ao se comparar o consumo do grupo de sobrepeso e obesidade (limite inferior 0,15 e limite superior 1,36).

Ao questionar o consumo de refrigerante e sucos industrializados, verificou-se, que a maioria dos entrevistados (127 pessoas ou 33,3\%) consome todos os dias da semana; 107 pessoas (28,1\%) não consomem nenhum dia da semana; 43 pessoas $(11,3 \%)$ consomem um dia por semana; 41 pessoas $(10,8 \%)$ consomem três dias por semana; 40 pessoas (10,5\%) consomem dois dias por semana; 14 pessoas $(3,7 \%)$ consomem quatro dias por semana; 7 pessoas (1,8\%) consomem cinco dias por semana e 2 pessoas $(0,5 \%)$ consomem seis dias por semana.

Referente ao consumo de doces, a maioria das pessoas referiram não consumir durante a semana (152 pessoas ou 39,9\%); 38 pessoas (10\%) consomem um dia por semana; 40 pessoas $(10,5 \%)$ consomem dois dias por semana; 26 pessoas $(6,8 \%)$ consomem três dias por semana; 15 pessoas $(3,9 \%)$ consomem quatro dias por semana; 18 pessoas $(4,7 \%)$ consomem cinco dias por semana; 3 pessoas $(0,8 \%)$ consomem seis dias por semana e 89 pessoas $(23,4 \%)$ referiram comer todos os dias da semana.

Finalizando o consumo alimentar, os participantes também foram questionados sobre a frequência com a qual substituem suas refeições principais por algum fastfood, como por exemplo, pizzas, lanches, salgados fritos e assados, lasanha congelada, entre outros. Verificou-se que 210 pessoas $(55,1 \%)$ não consomem na semana; 76 pessoas (20\%) consomem um dia da semana; 51 pessoas $(13,4 \%)$ consomem dois dias da semana; 24 pessoas (6,3\%) consomem três dias por semana; 10 pessoas $(2,6 \%)$ consomem quatro dias por semana; 5 pessoas (1,3\%) consomem 
cinco dias por semana; 5 pessoas $(1,3 \%)$ consomem seis dias por semana e nenhuma pessoa referiu consumo diário. Na análise estatística houve diferença significativa no consumo desse grupo alimentar na população entre adultos e idosos (limite inferior $0,48$ e limite superior 0,95$)$.

A análise de regressão não apresentou nenhuma evidencia de diferença significativa na comparação entre o consumo de adultos e idosos do grupo de hortaliças cruas, hortaliças cozidas, frango, peixe, suco natural, frutas, refrigerantes, doces e água. Também não houve diferença significativa na comparação entre os grupos alimentares e a classificação nutricional dos grupos de hortaliças cruas, peixe, frutas, refrigerante, doces, fast-food e água. Na comparação entre os grupos alimentares e a classificação nutricional dos idosos, nenhum grupo alimentar mostrou evidencia de diferença.

\subsubsection{Ingestão Hídrica}

A ingestão de água foi questionada em volume total ingerido diariamente, sendo utilizadas referencias como copos ou garrafas, para modelos de estimativa.

O consumo mais prevalente da população estudada foi de mil e duzentos a dois mil $\mathrm{ml}$, sendo referido este volume por 199 pessoas $(52,2 \%)$. O consumo de seiscentos a mil e duzentos $\mathrm{ml}$ foi referido por 106 pessoas $(27,8 \%)$, o consumo menor que seiscentos $\mathrm{ml}$ foi referido por 45 pessoas $(11,8 \%)$ e o consumo maior que dois mil $\mathrm{ml}$ foi referido por 31 pessoas $(8,2 \%)$.

\subsection{Classificação do Estado Nutricional}

O estado nutricional foi classificado segundo o índice de massa corporal proposto pelo Ministério da Saúde, separado pelas classificações etárias (adulto e idoso) e de sexo (masculino e feminino). (Tabela 5).

Na população adulta (20 a 59 anos) do sexo masculino, um indivíduo (1,5\%) foi classificado como baixo peso; nove indivíduos (13,2\%) etróficos; 31 indivíduos (45,6\%) com sobrepeso e 27 indivíduos (39,7\%) com obesidade. Na população idosa (maior de 60 anos) do sexo masculino, um indivíduo (3,5\%) foi classificado com baixo peso; 13 indivíduos (44,8\%) como eutróficos e 15 indivíduos $(51,7 \%)$ como sobrepeso. 
Na população adulta (20 a 59 anos) do sexo feminino, dois indivíduos $(0,9 \%)$ foram classificados como baixo peso; 44 indivíduos (19,6\%) etróficos; 78 indivíduos (34,8\%) com sobrepeso e 100 indivíduos (44,7\%) com obesidade. Na população idosa (maior de 60 anos) do sexo feminino, três indivíduos (5\%) foram classificados com baixo peso; 17 indivíduos $(28,3 \%)$ como eutróficos e 40 indivíduos $(66,7 \%)$ como sobrepeso.

Desta forma, observa-se que em ambos os grupos predominou o excesso de peso (sobrepeso e obesidade) em relação a eutrofia e baixo peso.

Tabela 5. Estado Nutricional segundo IMC, em usuários adultos e idosos, segundo o sexo, que utilizam a ESF de Bebedouro, SP - 2017.

\begin{tabular}{lcccccc}
\hline Estado & \multicolumn{2}{l}{ Homens } & \multicolumn{2}{c}{ Mulheres } & \multicolumn{2}{c}{ Total } \\
Nutricional & $\mathrm{n}$ & $\%$ & $\mathrm{n}$ & $\%$ & $\mathrm{n}$ & $\%$ \\
\hline Adultos & & & & & & \\
Baixo Peso & 1 & 1,5 & 2 & 0,9 & 3 & 1,0 \\
Eutrofia & 9 & 13,2 & 44 & 19,6 & 53 & 18,2 \\
Sobrepeso & 31 & 45,6 & 78 & 34,8 & 109 & 37,3 \\
Obeso & 27 & 39,7 & 100 & 44,7 & 127 & 43,5 \\
\hline Total & 68 & 100 & 224 & 100 & 292 & 100 \\
\hline Idosos & 1 & 3,5 & 3 & 5,0 & 4 & 4,5 \\
Baixo Peso & 13 & 44,8 & 17 & 28,3 & 30 & 33,7 \\
Eutrofia & 15 & 51,7 & 40 & 66,7 & 55 & 61,8 \\
\hline Sobrepeso & 15 & 100 & 60 & 100 & 89 & 100 \\
\hline Total & 29 & & & & &
\end{tabular}




\section{Capítulo 4}

\section{Discussão}

Foram identificados 23314 adultos acima de 20 anos no SIAB, dos quais 378 seriam entrevistados de acordo com o cálculo amostral. A pesquisa foi muito bem aceita pela população e o estudo abordou 381 indivíduos. Não houve recusas neste estudo devido a colaboração dos profissionais das ESFs e por conhecerem o entrevistador, o que promoveu uma participação efetiva.

A distribuição da população estudada, por sexo, mostrou que apenas 25,5\% da amostra era de indivíduos do sexo masculino. Em estudo sobre a caracterização da demanda em uma unidade de saúde da família, Pimentel et al ${ }^{39}$ encontraram proporções parecidas em relação à demanda de procura, que foi de 27,8\% para o sexo masculino e $72,2 \%$ para o sexo feminino. Os autores referem, que entre as causas da maior predominância de mulheres pode estar a menor participação destas no trabalho formal e maior tempo disponível, além de possuírem uma maior preocupação com o autocuidado. ${ }^{39}$

No estudo 33,9\% dos indivíduos pertenciam à faixa etária dos 20 - 39 anos, 44\% à faixa etária dos 40 - 59 anos e 22,1\% à faixa etária de 60 anos ou mais. A proporção de adultos jovens (20-39 anos) na amostra mostrou-se semelhante à da população brasileira no PNAD $2015^{40}$ que foi de 30,7\%. Já a proporção de adultos (40-59 anos) e de idosos ( $\geq 60$ anos) neste estudo foi maior do que a no PNAD (25,4\% e 14,3\%, respectivamente) onde foi de $44 \%$ e $22,1 \%$.

Em relação ao nível de escolaridade, a população do estudo apresenta menor taxa de analfabetismo ou alfabetismo funcional do que a média do PNAD, sendo 17,1 e $25,1 \%$ respectivamente. ${ }^{40} \mathrm{~A}$ proporção de pessoas com somente 0 ensino fundamental completo de acordo com a PNAD 2015, foi de 52,6\% e neste estudo de $12,9 \%$. Observou-se maior proporção de pessoas com ensino médio completo e menor com ensino superior completo em relação ao PNAD $(38,6 \%$ versus $26,4 \%$ e 
$6,8 \%$ versus $13,5 \%$, respectivamente). Há preocupação em completar a educação básica (ensino médio completo) por parte dos participantes, porém o ensino superior não. A justificativa para isso é que cursar o ensino médio facilita a entrada no mercado de trabalho, mas não possuem tempo e renda suficiente para continuar os estudos.

O município de onde provém a população estudada ocupa a posição 337 na classificação das cidades de acordo com o produto interno bruto (PIB), considerando que a lista apresentou 658 municípios, a cidade estudada ocupa a segunda metade da lista, o que mostra ser um município com uma população de menor renda. ${ }^{41}$ Outro fator relevante se refere à população de estudo, que era composta por indivíduos que utilizam o sistema público de saúde, não possuem renda suficiente para recorrer ao sistema privado de saúde, fato que é mais frequente nas classes $A$ e B.

Para OMS um dos fatores de risco para o desenvolvimento de DCNT é a ingestão abusiva de álcool, não só apresenta um risco DCNTs, como também pode elevar a incidência de acidentes e violências. ${ }^{32}$

Nos últimos anos o consumo abusivo de bebidas alcoólicas, vem se mantendo estável, sendo que em 2006 era equivalente a 15,7\% da população e em 2016 19,1\%.42 Uma das causas prováveis dessa estabilidade são as políticas públicas que desestimularam ao longo dos anos o consumo abusivo de álcool, através de campanhas e legislações. ${ }^{43}$

A presente pesquisa mostrou que $27,9 \%$ dos participantes entrevistados, apresentavam um consumo de álcool de uma ou mais vezes por semana, valor um pouco acima do encontrado pela Pesquisa Nacional de Saúde de 2013 que foi de $24 \%{ }^{32}$

As perguntas do questionário referente ao consumo de álcool, apontavam para respostas autorreferidas, que em muitos momentos, podem se caracterizar como um viés, ao levar em consideração que nem sempre o entrevistado sentia-se confortável em responder como uma afirmativa. Dentre os $59,8 \%$ dos entrevistados que referiam nunca consumir álcool, a maior justificativa estava ligada a fatores religiosos.

Em relação ao tabagismo, ao longo dos anos, também foram realizadas muitas políticas e campanhas que estimularam a cessação do hábito de fumar, como exemplo a "Lei Antifumo", que proíbe o uso de produtos fumígenos em ambientes fechados públicos ou privados de acesso coletivo e o aumento das taxas sobre o produto ${ }^{44}$, no entanto, ainda hoje milhões de pessoas apresentam esse vício. De acordo com a PNS os usuários com maior percentual de uso de tabaco, corresponde 
ao sexo masculino, com $19,2 \%$ da população, sendo o sexo feminino, correspondente a $11,2 \%$ dos tabagistas. ${ }^{32}$

Nesta pesquisa, os tabagistas representaram 15,8\% da população, e os exfumantes a 34,7\% da população. O resultado para prevalência de tabagistas foi similar ao encontrado pela PNS de 15\%. Entretanto para ex-fumante, o valor apresenta uma maior diferença com a PNS que encontrou a prevalência de $17,5 \%$. Dois prováveis motivos para a prevalência mais elevada são o fator religião e o acompanhamento pela Estratégia de Saúde da Família, que realiza trabalhos voltados para cessação do tabaco.

A percepção do estado de saúde foi avaliada por questionário semiestruturado, onde o entrevistado poderia classificar seu estado de saúde como muito bom, bom, regular, ruim e muito ruim. Nesta pesquisa $48 \%$ da amostra auto avaliou seu estado de saúde como bom ou muito bom. Este resultado encontra-se um pouco abaixo do que a média nacional encontrada pela $\mathrm{PNS}^{26}$, que foi de $66,1 \%$ e mais baixo ainda quando comparado ao estado de São Paulo, onde 71,8\% dos entrevistados referiram uma saúde boa ou muito boa.

Durante as entrevistas, pode-se notar que quanto maior a renda e nível de escolaridade melhor era a auto percepção de saúde. Esta mesma observação pode ser encontrada nos resultados da $\mathrm{PNS}^{32}$, onde os indivíduos que declararam uma autoavaliação de saúde como boa ou muito boa, 49,2\% apresentavam nível de escolaridade de sem instrução a fundamental incompleto e 84,1\% apresentavam ensino superior completo. Isto pode sugerir que quanto maior nível de instrução melhor a autoavaliação de saúde.

Em relação ao padrão de sono, a pesquisa encontrou que $73,5 \%$ dos entrevistados dormem menos do que seis horas ininterruptas diariamente, número bem expressivo quando comparado a pesquisas sobre o mesmo assunto que era de $46 \%{ }^{45}$. Estudos apontam que pessoas que possuem seis horas ou menos de sono diário, tem maior propensão para o desenvolvimento de hipertensão, doenças cardiovasculares, obesidade, entre outras morbidades ${ }^{45,46}$. Durante as entrevistas as maiores queixas da baixa carga horária de sono foram: insônia; excesso de ruídos noturnos, causado pelo tráfico; preocupação com familiares fora de casa.

De 2009 a 2016 cresce o indicador da prática de atividade física em tempo livre, que passou respectivamente de $30,3 \%$ para $37,6 \%$; esta prática diminui ao longo da 
idade passando de $52 \%$ dos 18 aos 24 anos para $22 \%$ na faixa etária dos 65 anos ou mais. ${ }^{42}$

Em relação à prática de atividade física, observa-se que a maioria dos indivíduos são sedentários ou não praticam a quantidade semanal recomendada pela Organização Mundial de Saúde - OMS que é a somatória de 150min de atividade leve ou moderada por semana ${ }^{16}$. Neste trabalho $23,1 \%$ dos indivíduos referiram praticar 150 minutos ou mais de atividade física semanal, valor um pouco acima do percentual nacional que foi de $22,5 \%$ de acordo com a PNS e próximo ao porcentual do estado de São Paulo que foi de $23,5 \%{ }^{47}$. O cenário encontrado neste estudo não é muito diferente do cenário brasileiro. De acordo com o diagnostico nacional do esporte, do Ministério do Esporte 45,9\% da população brasileira é sedentária, sendo que a maior prevalência de inatividade física está entre as mulheres. ${ }^{48}$ De acordo com a mesma pesquisa, os principais motivos para inatividade física foram: falta de tempo/outras prioridades 69,8\%; problema de saúde ou idade 12,5\%; cansaço/preguiça/ desmotivação 7\%; falta de resultados e socialização 6,1\%; falta de instalações para prática 3,2\%; fatores econômicos 1,4\%. Durante as entrevistas os participantes relataram os mesmos motivos da pesquisa acima citada.

O hábito de assistir TV é considerado um comportamento sedentário, que está relacionado com o maior desenvolvimento de doenças crônicas não transmissíveis.

Nessa população de estudo, encontrou-se que 54,8\% ficam três horas ou mais em frente à TV, valor expressivamente maior que o porcentual nacional, que foi de $28,9 \%$.

Existe forte relação entre o consumo excessivo de sal e sódio ( $>6 \mathrm{~g}$ diárias e $2,4 \mathrm{~g}$ ) com o aumento na prevalência das DCNT, como por exemplo a hipertensão ${ }^{47}$. Nesta pesquisa foi avaliada a percepção do consumo diário de sal e sódio em cinco categorias; os resultados mostraram que 17,4\% apresentaram um consumo alto ou muito alto, sendo este consumo um pouco mais elevado que o encontrado na PNS que foi de $14,2 \% 32$.

Em relação ao consumo alimentar, os entrevistados foram questionados a respeito dos principais grupos alimentares presentes no hábito brasileiro.

O consumo regular de feijão pela população brasileira é maior no sexo masculino, na faixa etária dos 40 a 59 anos e nos indivíduos de menor escolaridade ${ }^{32}$.

A ingestão de feijão vem caindo nos últimos anos, sendo que passou de 67,5\% em 2012 para $61,3 \%$ em $2016^{42}$. O consumo avaliado pela população deste estudo 
foi de $65,9 \%$ dos entrevistados, resultado um pouco superior ao encontrado no relatório VIGITEL de $2016^{39}$, que é de $61,3 \%$, e inferior ao da PNS de $2013^{32}$ que foi de $71,9 \%$. Na PNS ${ }^{32}$ a ingestão de feijão foi maior no sexo masculino $(76,8 \%)^{32}$, o mesmo foi encontrado nesta pesquisa, onde, $78,4 \%$ dos homens e $61,9 \%$ das mulheres consomem mais de cinco vezes na semana.

O consumo regular de frutas e hortaliças, considerado pela OMS $400 \mathrm{~g}$ ao dia ou cinco porções, cresce nos últimos anos, passando de 33\% em 2008 para 35,2\% em 2016. No entanto, este crescimento ainda é insatisfatório, pois apenas 1 entre 3 adultos consomem frutas e hortaliças 5 dias por semana. ${ }^{42,32}$

$\mathrm{Na} \mathrm{PNS}^{32}$ o porcentual de pessoas que consomem 5 porções diárias de frutas e hortaliças foi de 37,3\%. De acordo com o VIGITEL ${ }^{39}$ de 2016, cerca de $33 \%$ adultos consomem frutas e hortaliças pelo menos cinco dias da semana. Nesta pesquisa 0 consumo desse grupo alimentar foi bem menos expressivo, equivalente a $16,5 \%$. Durante as entrevistas, as principais queixas em relação ao não consumo foram: custo, falta de hábito e preguiça de higienizar e cozinhar.

De acordo com a PNS ${ }^{32}$, percebe-se que o consumo de hortaliças e frutas na quantidade recomendada é maior na população feminina, na faixa etária dos 60 anos ou mais e com ensino superior completo.

Em relação às carnes, bovina, suína, frango e peixe, foi questionado o seu consumo em número de vezes por semana, bem como a gordura aparente. 0 consumo de peixe ao menos uma vez na semana foi referido por $18,2 \%$ dos entrevistados, porcentual muito abaixo quando comparado ao consumo nacional encontrado pela $\mathrm{PNS}^{32}$, que foi de $54,6 \%$. Uma das principais justificativas durante as entrevistas para o baixo consumo semanal, foi referente a questões econômicas.

Os indivíduos que referiram o consumo de gordura aparente de carne ou frango nesta pesquisa foi de $50,9 \%$, onde $63,9 \%$ são do sexo masculino e a maioria adultos jovens, sendo superior ao encontrado na $\mathrm{PNS}^{32}$ onde foi de $37,2 \%$, sendo $47,2 \%$ de homens.

Em relação aos alimentos industrializados, ou seja, as refeições prontas, os participantes foram questionados sobre a substituição das refeições principais (almoço e/ou jantar) por este tipo de alimentação, nesta pesquisa 44,9\% dos entrevistados referiram consumir ao menos uma vez na semana, porém nenhum participante referiu consumir sete vezes na semana, resultado muito abaixo ao encontrado pelo VIGITEL 2016 em São Paulo Capital $(11,2 \%)^{42}$. Esse tipo de 
alimentação deve ser evitado devido às baixas quantidades de vitaminas, fibras e minerais e grandes de gorduras saturadas, sódio e carboidratos simples, sendo consideradas dietas de baixa qualidade nutricional, que corrobora com 0 aparecimento de DCNT ${ }^{49,50}$ Dentre os que não consumem FastFood, justificaram que são alimentos mais caros e não acessíveis para famílias numerosas.

O hábito de consumir alimentos não saudáveis como doces e refrigerante regularmente, ou seja, fazer o uso pelo menos cinco dias da semana, também foi questionado. A PNS 32 encontrou que $21,7 \%$ tinham o consumo regular de doces, um pouco abaixo do encontrado nesta pesquisa que correspondeu a $28,9 \%$, já o consumo de refrigerante foi referido por $35,5 \%$ dos indivíduos entrevistados, sendo um pouco superior ao encontrado pela PNS $23,4 \%$, onde os homens possuíam um consumo mais frequente $(26,6 \%)$ do que as mulheres $(20,5 \%)$, contrapondo ao encontrado nesta pesquisa que foi maior em mulheres (35,5\%) do que nos homens (34\%).

Em todo o mundo, principalmente nos países subdesenvolvidos, o estilo alimentar e a oferta de nutrientes estão mudando em alta velocidade. Essas mudanças se referem principalmente a troca de alimentos com menor grau de processamento (arroz, feijão, legumes, frutas, carnes frescas) por alimentos com maior grau de processamento (biscoitos, conservas, carnes processadas, embutidos). Essa mudança se deve principalmente a maior modernização dos centros urbanos e falta de tempo para se dedicar as preparações culinárias caseiras e mais saudáveis. Como consequência, observa-se um desequilíbrio na oferta de nutrientes, ora alguns com ingestão menor do que o necessário - como carboidratos complexos, vitaminas, sais minerais, fibras e proteínas - e ora outros com ingestão maior do que necessário - como carboidratos simples, gordura saturada e sódio-.28

O consumo de água recomendado no Guia Alimentar para População Brasileira 2006 é de 6 a 8 copos (mil e duzentos $\mathrm{ml}$ à dois mil $\mathrm{ml}$ ) diários ${ }^{28}$, nesta pesquisa mais da metade dos entrevistados (60,3\%) consomem o recomendado pelo Ministério da Saúde, porém 39,7\% tomam menos que 6 copos diários (mil e duzentos ml). Os riscos de desidratação ou decorrências por ela causada depende de uma pesquisa mais detalhada que contemple o consumo de água, os líquidos em geral e os contidos nos alimentos, conforme recomendado pelas DRIs (Dietary Reference Intakes) ${ }^{51}$ incluindo o ambiente, suor, peso e idade.

A obesidade considerada um problema de saúde pública mundial ${ }^{1}$, está se tornando uma pandemia, onde acomete várias regiões do planeta. Levantamentos 
realizados no Brasil pelo VIGITEL, detalham o aumento de 7,1\% nos últimos dez anos (2006 a 2016) de 11,8\% para 18,9\%. Em São Paulo, a pesquisa de Vigilância de fatores de risco e proteção para doenças crônicas por inquérito telefônico (VIGITEL) encontrou que 53,9\% dos indivíduos estão em excesso de peso, 58\% homens e 51\% mulheres, dados esses mais expressivos do que os encontrados nesta pesquisa, onde $43,1 \%$ estão em sobrepeso (47,4\% dos homens e 41,6\% das mulheres). Quanto à obesidade, pelo VIGITEL ${ }^{42}$ em São Paulo, a taxa foi de 18,5\%, sendo 15\% em homens e em $21 \%$ mulheres; o encontrado nesta pesquisa foi muito expressivo, quase o dobro, sendo $33,3 \%$ de obesidade $(27,8 \%$ em homens e $35,2 \%$ em mulheres). 



\section{Capítulo 5}

\section{Considerações Finais}

Com todos os dados encontrados por essa pesquisa, pode-se observar a importância do investimento de recursos públicos em políticas que priorizem a qualidade do estilo de vida e adequação da classificação do estado nutricional para eutrofia.

De acordo com os dados encontrados conclui-se que a população que mais frequenta as unidades de ESF do município estudado é a do sexo feminino, da faixa etária dos 20 aos 39 anos, com ensino médio completo, de classe econômica D-E.

Em relação aos hábitos gerais dessa população a maior parte dorme menos de seis horas por noite e é sedentária com permanência de três horas em frente à TV, não tabagista, não faz ingestão do uso de álcool e se considera com um bom estado de saúde. Percebe-se também que essa população se caracteriza por um consumo alimentar com presença de hortaliças, frutas, leite, feijão, carnes (vermelha e frango) e refrigerante quase todos os dias. A maioria demonstra não consumir suco natural, peixes, doces e fastfood. O consumo de água é menor que dois litros ao dia pela maioria dos entrevistados.

Em relação à classificação do estado nutricional segundo o índice de massa corporal, observa-se que a maior parte dos indivíduos adultos está classificado como obeso e a maior parte dos indivíduos idosos está classificado como sobrepeso.

Sendo assim, torna-se nítida a necessidade de campanhas que despertem o interesse da população masculina pela busca de cuidado e da faixa maior de 40 anos para ambos os sexos, considerando que nessa faixa há maior vulnerabilidade para doenças crônicas não transmissíveis, implementação de políticas que estimulem 
melhor qualidade e quantidade de horas de sono e maior prática de atividade física, visando à diminuição de peso.

Quanto ao consumo alimentar, são necessárias políticas que fomentem principalmente a redução do consumo de bebidas açucaradas e de alimentos industrializados propiciando o aumento do consumo de alimentos saudáveis, tais como peixes, hortaliças e frutas, assim como o aumento da ingestão de água.

Contudo, são necessários outros estudos que explorem o estilo de vida da população e que utiliza o sistema de saúde de modo a contribuir com evidências científicas adequadas para criar, elaborar e aplicar novas políticas. 


\section{Referências Bibliográficas}

1. Braulio VB, Furtado VCS, Silveira MG, Fonseca MH, Oliveira JE. Comparison of body composition methods in overweight and obese Brazilian women.Arq.Bras.EndocrinolMetab. Junho 2010; 54(4): 398-405.

2. Munhoz LO, Sorpreso ICE, Nogueira MCC, Simões RS, Soares JJM, Baracat EC. How to evaluate quality of life in overweight and obese women during climacterium?.Rev. Assoc. Med. Bras. Outubro 2014; 60(5): 484-489.

3. World Health Organization. Obesity and overweight.Fact sheet $\mathrm{N}^{\circ} .311$. Disponível em (http://www.who.int/mediacentre/factsheets/fs311/en/). Acesso em 15/10/2016.

4. Associação Brasileira para o Estudo da Obesidade e da Síndrome Metabólica. Mapa da Obesidade. 2009. Acesso 30 Outubro 2015. Disponível em (http://www.abeso.org.br/atitude-saudavel/mapa-obesidade). Acesso em 05/05/2016.

5. Bernardo CO, Boing AF, Vasconcelos FAG, Peres KG, Peres MA. Association between tooth loss and obesity in Brazilian adults: a population-based study. Rev. Saúde Pública. Outubro 2012; 46(5): 834-842.

6. Garcez MR, Pereira JL, FontanelliMM,Marchioni DML, Fisberg RM. Prevalência de Dislipidemia Segundo Estado Nutricional em Amostra Representativa de São Paulo.Arq.Bras.Cardiol.Dezembro 2014;103(6): 476-484.

7. Vigitel 2016. Obesidade cresce $60 \%$ em dez anos no Brasil. Portal Brasil. Abril 2017. Disponível em (http://www.brasil.gov.br/saude/2017/04/obesidadecresce-60-em-dez-anos-no-brasil). Acesso 10/08/2017.

8. Rosa MI, Silva FML, Giroldi SB, Antunes GN, Wendland EM. Prevalência e fatores associados à obesidade em mulheres usuárias de serviços de prontoatendimento do Sistema Único de Saúde no sul do Brasil. Ciênc. Saúdecoletiva. Maio 2011; 16(5): 2559-2566.

9. Steyn NP, Mchiza ZJ. Obesity and the nutrition transition in SUB-Saharan Africa. Ann.N.Y.Acad. Sci. 2014; 88-101

10. De Oliveira ML, Santos LMP, da Silva EM. Direct Healthcare Cost of Obesity in Brazil:Na Applications of the Cost-of-Illness Method from the Perspective of the Public Health System in 2011.PLoS ONE. April 2015; 10(4):e0121160

11.Peruchi CTR, Poli-Frederico RC, Cardelli AAM, Fracasso MLC, Bispo CGC, Neves-Souza RD et al. Association between oral health status and central obesity among Brazilian independent-living elderly. Braz. Oral res. July 2016; 30(1):e116 
12. Folchetti LGD, Silva IT da, Almeida-Pititto B de, et al. Nutritionists' Health Study cohort: a web-based approach of life events, habits and health outcomes. BMJ Open 2016; 6:e012081.

13. Veronese N, Li Y, Manson JE, Willet WC, Fontana L, Hu FB. Combined associations of body weight and lifestyle factors with all cause and cause specific mortality in men and women: prospective cohort study. The BMJ. November 2016; 355:i5855.

14. Silva DAS, Pereira IMM, Almeida MB, Silva RJS, Oliveira ACC. Estilo de Vida de Acadêmicos de uma Universidade Pública do Estado de Sergipe, Brasil. Revista Brasileira de Ciências e Esporte. Março 2012; 34(1):53-67.

15. Martins MCC, Ricarte IF, Rocha CHL, Maia RB, Silva VB, Veras AB, et al. Pressão arterial, excesso de peso e nível de atividade física em estudantes de universidade pública. Arq. Bras. Cardiol. Agosto 2010; 95(2): 192-199.

16. World Health Organization. Global recommendations on physical activity for health.Geneva,2010;(4):23-33

17. Väistö J, Eloranta AM, Viitasalo A, Tompuri T, Lintu N, KarjalainenP,et al. Physical activity and sedentary behaviour in relation to cardiometabolic risk in children: cross-sectional findings from the Physical Activity and Nutrition in Children (PANIC) Study. The International Journal of Behavioral Nutrition and Physical Activity, April 2014;11- 55.

18. Pinho CPS, Diniz AS, Arruda IKG, Lira PIC, Leopoldina AS, Gonçalves FCLSP et al . Excesso de peso em adultos do Estado de Pernambuco, Brasil: magnitude e fatores associados. Cad. Saúde Pública. Dezembro 2011; 27(12): 2340-2350.

19. Correia LL, Silveira DMI, Silva AC, Campos JS, Machado MMT, Rocha HAL, et al. Prevalência e determinantes de obesidade e sobrepeso em mulheres em idade reprodutiva residentes na região semiárida do Brasil. Ciênc. saúde coletiva Janeiro $2011 ; 16(1)$ : 133-145.

20. Ferreira NL, Mingoti SA, Jaime PC, Lopes ACS. Efetividade de intervenção nutricional em mulheres com excesso de peso na Atenção Primária à Saúde. Rev. Nutr. Dezembro 2014; 27(6): 677-687.

21. Ministétio da Saúde. Secretaria de Atenção à Saúde. Política Nacional de Atenção Básica. Brasília (DF); 2012.

22. Ministério da Saúde. Portaria no 154 de 24 de janeiro de 2008. Cria os Núcleos de Apoio à Saúde da Família - NASF. Diário Oficial da União. 25 jan 2008; Seção 1:2

23. Ministério da Saúde. Academia de Saúde. Brasília (DF); 2014b 
24. Sá NNB, Moura EC. Excesso de peso: determinantes sociodemográficos e comportamentais em adultos, Brasil, 2008. Cad. Saúde Pública 2011; 27(7): 1380-1392.

25. Pinho CPS, Diniz AS, Arruda IKG, Lira PIC, Cabral PC, Siqueira LAS et al. Consumo de alimentos protetores e preditores do risco cardiovascular em adultos do estado de Pernambuco. Rev. Nutr. Junho 2012; 25(3): 341-351.

26. Souza LV, Ornellas FH. Avaliação do Conhecimento Nutricional de Indivíduos Eutróficos, Sobrepesos e Obesos e Sua Associação com o Estado Nutricional. Rev. Bras. Obesidade, Nutrição e Emagrecimento. São Paulo. Abril 2011. 26(5): 40-47.

27. Ofori-Asenso R, Agyeman AA, Laar A, Boateng D. Overwheight and obesity epidemic in Ghana - a systematic review and meta-analysis. BMC Public Health. December 2016; 16:1239

28. Brasil. Ministério da Saúde. Secretaria de Atenção à Saúde. Departamento de Atenção Básica. Coordenação-Geral da Política de Alimentação e Nutrição. Guia alimentar para população brasileira: promovendo a alimentação saudável. Brasília 2006. 210: 11-18.

29. Morais Neto OL de. Inquéritos Nacionais de Saúde: experiência acumulada e proposta para o inquérito de saúde brasileiro. Rev. bras. Epidemol. Maio 2008; 11(Suppl1):159-167.

30. Guideline: Sugars intake for adults and children. Geneva: World Health Organization; 2015

31. OPAS/OMS - Organização Pan-Americana da Saúde/Organização Mundial da Saúde. Brasil assume metas para frear crescimento da obesidade até 2019. Brasília (DF); 2017

32. IBGE - Instituto Brasileiro de Geografia e Estatística. Pesquisa Nacional de Saúde 2013: percepção do estado de saúde, estilos de vida e doenças crônicas. Rio de Janeiro: IBGE, 2014.

33. Malta DC, Andrade SSCA, Stopa SR, Pereira CA, Szwarcwald CL, Silva Junior JB da et al. Estilos de Vida da População Brasileira: resultados da pesquisa nacional de saúde,2013. Epidemol. Serv. Saúde. Junho 2015; 24(2): 217-226.

34. IBGE - Instituto Brasileiro de Geografia e Estatística. Censo Demográfico 2010. IBGE, 2010.

35. ABEP-Associação Brasileira de Empresas de Pesquisa. 2015. Critério de Classificação Econômica do Brasil.

36. Ministério da saúde. Secretaria de Atenção à Saúde. Departamento de Atenção Básica. Vigilância alimentar e nutricional - Orientações para a coleta e análise de dados antropométricos em serviços de saúde: Norma Técnica do Sistema 
de Vigilância Alimentar e Nutricional - SISVAN/Ministério da Saúde. Brasília (DF), 2011.

37. OpenBUGS version 3.2.3

38. R Core Team (2016). R: A language and environment for statistical computing. $R$ Foundation for Statistical Computing, Vienna, Austria. Disponível em https://www.R-project.org

39. Pimentel IRS, Coelho B de C, Lima JC, Ribeiro FG, et al. Caracterização da demanda em uma unidade de saúde da família. Rev. Bras. Med. Fam. comunidade. Florianópolis, 2011. 6(20):17-81.

40. IBGE- Instituto Brasileiro de Geografia e Estatística. Pesquisa Nacional por Amostra de Domicílio: síntese de indicadores 2015. Rio de Janeiro: IBGE, 2016.

41. IBGE- Instituto Brasileiro de Geografia e Estatística. Produto Interno Bruto dos Municípios. 2010-2015. Rio de Janeiro, 2017.

42. Brasil. Vigitel Brasil 2016: vigilância de fatores de risco e proteção para doenças crônicas por inquérito telefônico. Brasília: Ministério da Saúde; 2017.

43. Duailibi $\mathrm{S}$, Laranjeira $\mathrm{R}$. Políticas públicas relacionadas às bebidas alcoólicas. Rev. Saúde Pública. Outubro2007; 41(5): 839-848.

44. Brasil. Portal da Saúde - SUS. Lei Antifumo: Número de Fumantes Passivos no Trabalho cai 34,4\% nos últimos anos. 2016.

45. Justin TS, David C. Sleep Insomnia, and Hypertension: current findings and future directions. Journal of the American Society of Hypertension. Novembro, 2016. 1-8

46. Grant B, Suad FG, Liza TG. Short Sleep Duration is Associated with Obesity in Hispanic Manufacturing Workers. Journal of Health Care for the Poor and Underserved. Nov 2017. 28 (4): 1304-1313

47. SEADE - Sistema Estadual de Análise de Dados. Percepção do Estado de Saúde, Estilo de Vida e Doenças Crônicas: Uma Comparação entre Brasil e Estado de São Paulo. Dezembro 2015; 33: 11

48. Ministério do Esporte. Diagnóstico Nacional do Esporte no Brasil. Brasília (DF), 2013.

49. World Health Organization. Diet, nutrition and the prevention of chronic disease. Geneva, 2003. 160p

50. Wood GL. Diet, Obesity and Asthma. Annals of the American Thoracic Society. Nov 2017; 14 (5). 
51. IOM. NAS. Dietary Reference Intakes for Water, Potassium, Sodium, Chloride and Sulfate; 2005. 



\section{Apêndice A}

\section{Questionário sociodemográfico e econômico}

\section{(ABEP 2016)}

Ficha:

ESF:

1) Qual é a sua idade? anos

2) Qual é o seu sexo?

(1) Homem

( 2 ) Mulher

3) Qual é o seu estado civil?
(1) Solteiro(a)
( 2 ) Casado(a) no civil
( 3 ) União Estável
( 4 ) Separado(a)
( 5 ) Viúvo(a)

4) Qual é o seu nível de escolaridade?
(1) Analfabeto/Fundamental I incompleto
( 2 ) Ensino fundamental I/Fundamental II incompleto
( 3 ) Ensino fundamental II/ Médio incompleto
( 4 ) Ensino médio/Superior incompleto
( 5 ) Ensino superior completo 
5) Possui algum desses itens? Qual a quantidade

\begin{tabular}{|c|l|l|l|l|l|}
\hline \multirow{2}{*}{ Itens } & \multicolumn{5}{|c|}{ Quantidade } \\
\hline & 0 & 1 & 2 & 3 & 4 ou + \\
\hline Banheiro & & & & & \\
\hline Empregada Mensalista & & & & & \\
\hline Automóvel & & & & & \\
\hline Computador & & & & & \\
\hline Lava Louça & & & & & \\
\hline $\begin{array}{c}\text { Geladeira } \\
\text { Freezer (aparelho } \\
\text { independente ou parte } \\
\text { da geladeira duplex) }\end{array}$ & & & & & \\
\hline $\begin{array}{c}\text { Máquina de lavar } \\
\text { roupa }\end{array}$ & & & & & \\
\hline DVD & & & & & \\
\hline Micro-ondas & & & & & \\
\hline Motocicleta & & & & & \\
\hline Secadora de Roupa & & & & & \\
\hline
\end{tabular}

6) Possui Água Encanada?
(1) $\mathrm{Sim}$
(2) Não

7) Possui Rua Pavimentada?
(1) $\operatorname{Sim}$
(2) Não 


\section{Apêndice B}

\section{Questionário Pesquisa Nacional de Saúde (Módulo P Estilo de Vida)}

1. O (A) Sr.(a) gostaria de saber o peso e a altura?

(1) Sim

(2)Não

Peso: Altura:

2. Em quantos dias da semana o(a) costuma comer feijão?
( ) Dias
0 . Nunca ou menos de uma vez por semana

3. Em quantos dias da semana, o(a) sr(a) costuma comer salada de alface e tomate ou salada de qualquer outra verdura ou legume cru?
( ) Dias
0 . Nunca ou menos de uma vez por semana

4. Em quantos dias da semana, o(a) sr(a) costuma comer verdura ou legume cozido, como couve, cenoura, chuchu, berinjela, abobrinha? (sem contar batata, mandioca ou inhame)
( ) Dias
0 . Nunca ou menos de uma vez por semana

5. Em quantos dias da semana o(a) $\operatorname{sr}(a)$ costuma comer carne vermelha (boi, porco, cabrito)? (Se $5=0$, passe ao 7 . Se $5>0$, siga 6 .)
( ) Dias
0 . Nunca ou menos de uma vez por semana

6. Quando o(a) sr(a) come carne vermelha, o(a) sr(a) costuma:

$\begin{array}{ll}\text { 1. Tirar o excesso de gordura visível } & \text { 2. Comer com a gordura }\end{array}$

7. Em quantos dias da semana o(a) sr(a) costuma comer frango/galinha? (Se $7=0$, passe ao 9 . Se $7>0$, siga 8 .)
( ) Dias
0 . Nunca ou menos de uma vez por semana 
8. Quando o(a) $\operatorname{sr}(a)$ come frango/galinha, o(a) $\operatorname{sr}($ a) costuma:

$\begin{array}{ll}\text { 1. Tirar a pele } & \text { 2. Comer com a pele }\end{array}$

9. Em quantos dias da semana o(a) sr(a) costuma comer peixe?

( )Dias $\quad 0$. Nunca ou menos de uma vez por semana

10. Em quantos dias da semana o(a) sr(a) costuma tomar suco de frutas natural?

( )Dias $\quad$ 0. Nunca ou menos de uma vez por semana

11. Em quantos dias da semana o(a) sr(a) costuma comer frutas?

( )Dias $\quad$ o. Nunca ou menos de uma vez por semana

12. Em quantos dias da semana o(a) sr(a) costuma tomar refrigerante (ou suco artificial)?

( )Dias $\quad$ 0. Nunca ou menos de uma vez por semana

13. Em quantos dias da semana o(a) sr(a) costuma tomar leite? (não vale leite de soja)

( )Dias $\quad$ 0. Nunca ou menos de uma vez por semana

14. Em quantos dias da semana o(a) sr(a) come alimentos doces, tais como pedaços de bolo ou torta, doces, chocolates, balas, biscoitos ou bolachas doces?

( )Dias $\quad$ 0. Nunca ou menos de uma vez por semana

15. Em quantos dias da semana o(a) $\operatorname{sr}(a)$ substitui a refeição do almoço ou jantar por sanduiches, salgados ou pizzas?

)Dias

0 . Nunca ou menos de uma vez por semana

16. Considerando a comida preparada na hora e os alimentos industrializados, o(a) $\operatorname{Sr}(a)$ acha que o seu consumo de sal é: 

1. Muito alto
2. Alto
3. Adequado
4. Baixo
5. Muito baixo

17. Considerando o consumo de água, quantos copos o sr(a) ingere por dia?

( ) copos

18. Com que frequência o(a) $\operatorname{sr}(a)$ costuma consumir alguma bebida alcoólica? (Se 18 = a ou b, passe ao 20. Se 18= c, siga 19.)
a. Não bebo nunca
b. Menos de uma vez por mês
c. Uma vez ou mais por mês

19. Quantos dias por semana o(a) sr(a) costuma tomar alguma bebida alcoólica?

( )Dias $\quad$ 0. Nunca ou menos de uma vez por semana

20. Quantos dias por semana o(a) $\operatorname{sr}(a)$ costuma praticar exercício físico ou esporte? (Se 20=0, passe ao 23. Se 20>0, siga 21.)
( ) Dias
0 . Nunca ou menos de uma vez por semana

21. Qual o exercício físico ou esporte que o(a) $\operatorname{sr}(a)$ pratica com mais frequência? Entrevistador: Anotar apenas o primeiro citado
1. caminhada
2.musculação
3.ginastica aeróbica
4. hidroginástica
5. outros

22. Em geral, no dia que o(a) sr(a) pratica exercício ou esporte, quanto tempo dura esta atividade?

( )Horas ( )Minutos

23. Perto do seu domicílio, existe algum lugar público (praça, parque, rua fechada, praia) para fazer caminhada, realizar exercício ou praticar esporte?
a. Sim
b. Não

24. Em média, quantas horas por dia o(a) sr(a) costuma ficar assistindo televisão? 
1. Menos de 1 hora

3. Entre 2 horas e menos de 4 horas

5. Não assiste televisão
2. Entre 1 hora e menos de 2 horas

4. Entre 4 horas ou mais

25. Atualmente, o(a) sr(a) fuma algum produto do tabaco?
1. Sim, diariamente
2. Sim, menos que diariamente

3. Não fumo atualmente

26. E no passado, o(a) sr(a) fumou algum produto do tabaco?

1. Sim, diariamente

2. Sim, menos que diariamente

3. Não, nunca fumei

27. Em média, quantos cigarros industrializados ou de palha o(a) sr(a) fuma por dia ou por semana atualmente?
1. Três ou mais por dia
2. Um ou dois por dia
3. Um ou mais por semana
4. Menos que uma vez por semana
5. Não fumo

28. Durante os últimos 12 meses, o(a) sr(a) tentou parar de fumar?
1. Sim
2. Não
3. Não se aplica

29. Em relação ao sono, quantas horas ininterruptas o sr.(a) dorme por dia?

30. O (A) Sr.(a) classifica seu estado de saúde como?
1. Muito bom
2. Bom
3. Regular
4. Ruim
5. Muito Ruim
6. Não sabe7. Não quis informar 


\title{
Apêndice C
}

\section{Termo de Consentimento Livre e Esclarecido)}

\author{
Pesquisa: "Estilo de Vida e Classificação do Estado Nutricional de Usuários das \\ Estratégia de Saúde da Família de um Município do Interior Paulista" \\ Pesquisador Principal: Bianca Bartholo Júlio. Orientador: Prof. Dr. Laércio Joel Franco. \\ Telefone para contato: (16) $3602-2443$ ou (17) $3343-5116$ \\ Instituição a que pertencem: Departamento de Medicina Social da Faculdade de \\ Medicina de Ribeirão Preto da Universidade de São Paulo (USP) \\ Endereço: Av. Bandeirantes, 3900, CEP 14049-900, Ribeirão Preto - SP
}

Prezado(a) senhor(a),

Você está sendo convidada a participar da pesquisa "Estilo de Vida e Classificação do Estado Nutricional de Usuários das Estratégias de Saúde da Família de um Município do Interior Paulista". O principal objetivo do estudo é identificar o perfil nutricional e estilo de vida de pacientes frequentadores das Estratégias de Saúde da Família (ESF) do município de Bebedouro. Nessa pesquisa, passará por antropometria (peso e altura) e responderá ao pesquisador um formulário sócio demográfico e econômico e um questionário sobre estilo de vida (módulo P) da Pesquisa Nacional de Saúde (PNS) de 2013, com duração aproximada de 10 minutos. Com isso contribuirá para futuros projetos de promoção da saúde para população de Bebedouro. A sua participação nesta pesquisa é voluntária, tendo a senhor(a) a liberdade de se recusar a participar. Caso aceite participar, seu nome não aparecerá em qualquer etapa da análise dos dados assim como nos resultados da pesquisa, de forma a manter seu sigilo e privacidade. Caso concorde em participar, você também poderá desistir a qualquer momento e retirar seu consentimento, sem penalização alguma. Para manter sua privacidade e anonimato, os materiais e documentos de pesquisa serão armazenados em computadores protegidos por senha e de posse dos pesquisadores deste estudo, com acesso restrito a estes, não sendo divulgado a outras pessoas. Os formulários serão guardados em uma sala do Departamento de Medicina Social -FMRP-USP por um período de cinco anos e depois serão incinerados. Os resultados da pesquisa serão divulgados em publicações e eventos científicos, bem como para instituições relacionadas à saúde. Qualquer dado decorrente desse estudo será indenizado de acordo com as Leis vigentes do País. 
As possibilidades de risco do presente estudo são mínimas, podendo gerar um constrangimento ao saber seu peso e relatar seu estilo de vida. O benefício de sua participação no estudo contribuirá para futuras melhorias da saúde, através de atividades de promoção e educação em saúde.

Esse termo será assinado pela pesquisadora responsável e por você, em duas vias, sendo que uma via assinada ficará com você. Se desejar informações adicionais, você poderá contatar os pesquisadores através dos dados acima, ou através do Comitê de Ética em Pesquisa do Centro de Saúde Escola FMRP/USP pelo telefone (16) 33150009.

$\mathrm{Eu}$,

RG declaro ter lido o "Termo de Consentimento Livre e Esclarecido" e recebido uma cópia deste documento. Declaro ainda ter sido informada sobre os aspectos e dúvidas referentes à pesquisa, e concordo em participar como voluntária da pesquisa.

Bebedouro, de de

Assinatura da participante

Assinatura da pesquisadora

Nome da pesquisadora 


\title{
Apêndice D
}

\section{Manifestação de Anuência}

\author{
UNIVERSIDADE DE SÃO PAULO \\ FACULDADE DE MEDICINA DE RIBEIRÃO PRETO \\ DEPARTAMENTO DE MEDICINA SOCIAL
}

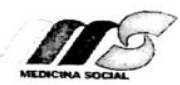

Av. Bandeirantes, 3900 - CEP 14049-900 - Ribeirão Preto - SP

Telefone: +55 (16) 36022433 - Fax: +55 (16) 36021526

Bebedouro, 13 de julho de 2016.

Prezado Diretor Dr. Antonio Carlos Feltrim,

Como é de seu conhecimento, a obesidade é um dos principais problemas de saúde pública mundial o estilo de vida pode estar associado com o excesso de peso. Devido essas informações se faz necessário a pesquisa do perfil nutricional e estilo de vida das pessoas atendidas nas Estratégias de Saúde da Família (ESFs) de Bebedouro, para elaboração de projetos futuros sobre promoção de saúde que sejam mais pontuais e eficazes.

Assim, venho por meio desta, solicitar manifestação de anuência de todas unidades de saúde da família para a realização da pesquisa intitulada "Perfil Nutricional e Estilo de Vida de pacientes freqüentadores das Estratégias de Saúde da Família de Bebedouor-SP", conforme projeto em anexo.

Pretendo realizar como método a antropometria e o questionário sobre estilo de vida da Pesquisa Nacional de Saúde no segundo semestre de $2016 \mathrm{em}$ todas as ESFs de Bebedouroprograma saberão de seu Perfil Nutricional e colaborarão para SP. Os participantes de promoção da saúde, os métodos e os procedimentos seguirão descritos no projeto em anexo.

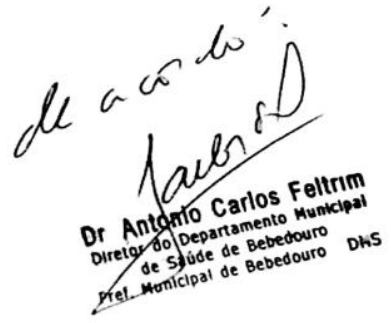

Atenciosamente,

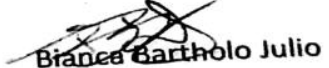
Mestranda na FMRP-USP 



\title{
Anexo
}

\section{Parecer Consubstanciado do CEP}

\author{
CENTRO DE SAÚDE ESCOLA \\ DA FACULDADE DE MEDICINA \\ DE RIBEIRÃO PRETO -
}

\section{PARECER CONSUBSTANCIADO DO CEP}

\section{DADOS DO PROJETO DE PESQUISA}

Título da Pesquisa: PERFÍL NUTRICIONAL E ESTILO DE VIDA DE PACIENTES FREQUENTADORES DAS ESTRATÉGIAS DE SAÚDE DA FAMÍLIA DE BEBEDOURO-SP

Pesquisador: BIANCA BARTHOLO JULIO

Área Temática:

Versão: 2

CAAE: 58313616.5 .0000 .5414

Instituição Proponente: Centro de Saúde Escola da Faculdade de Medicina de Ribeirão Preto - USP

Patrocinador Principal: Financiamento Próprio

\section{DADOS DO PARECER}

Número do Parecer: 1.715 .152

\section{Apresentação do Projeto:}

Tendo em vista o aumento mundial da obesidade e as mudanças no estilo de vida tais como: a falta de tempo para se alimentar adequadamente; praticar atividade física regularmente e ter boas horas de sono. Pode-se pressupor que esse novo estilo adquirido esteja impactando negativamente na saúde da população. Diante dessa realidade, se faz necessário, pesquisas que comprovem a relação do aumento de peso e o estilo de vida para futuras intervenções de promoção da saúde local, podendo servir de orientação para novas pesquisas.

\section{Objetivo da Pesquisa:}

Identificar o perfil nutricional e estilo de vida de pacientes maiores de 20 anos, freqüentadores das Estratégias de Saúde da Família (ESF) do município de Bebedouro. de vida de pacientes das ESF. Identificar se há associação entre o perfil nutricional e o estilo de vida e identificar número de tabagistas, alcoólatras e dependentes químicos.

\section{Avaliação dos Riscos e Benefícios:}

O estudo apresenta risco mínimo aos participantes, restrito ao vazamento de informações privadas

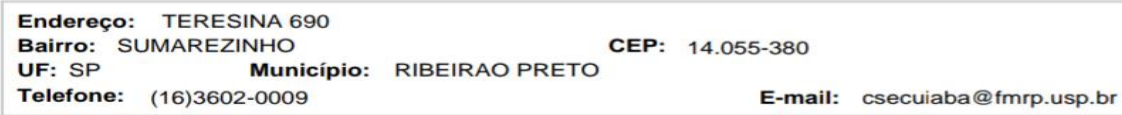




\section{CENTRO DE SAÚDE ESCOLA \\ DA FACULDADE DE MEDICINA DE RIBEIRÃO PRETO -}

Continuaçāo do Parecer: 1.715.152

ou problemas durante a pesagem dos pacientes ao subir na balança antropométrica, entretanto os pesquisadores informaram a existência desse risco no TCLE.

\section{Comentários e Considerações sobre a Pesquisa:}

O estudo será realizado junto as 11 equipes da Estratégia de Saúde da Família de Bebedouro-SP, sendo que o período de recrutamento dos voluntários será de três meses. A amostra será de 663 pacientes e o estudo está desenhado como transversal. Os dados que serão coletados junto aos pacientes serão: idade, genero, estado civil, escolaridade, profissão, hábitos alimentares, freqüência de consumo de frutas e hortaliças, consumo regular de feijão, de carnes, de refrigerante; prática de atividade física, consumo de álcool, tabagismo. Será acrescentado no questionário quatro variáveis: (i) doenças crônicas não transmissíveis: hipertensão, diabetes, dislipidemia, cardiopatia, insuficiência renal; (ii) peso em kg; (iii) altura em metros; (iv) IMC: obesidade, sobrepeso, eutrófico, magreza.

\section{Considerações sobre os Termos de apresentação obrigatória:}

As recomendações e sugestões foram atendidas pelos pesquisadores. TCLE adequado.

\section{Recomendações:}

Nenhuma.

Conclusões ou Pendências e Lista de Inadequações:

Nenhuma.

Considerações Finais a critério do CEP:

Este parecer foi elaborado baseado nos documentos abaixo relacionados:

\begin{tabular}{|c|c|c|c|c|}
\hline Tipo Documento & Arquivo & Postagem & Autor & Situaçãc \\
\hline $\begin{array}{l}\text { Informações Básicas } \\
\text { do Projeto }\end{array}$ & $\begin{array}{l}\text { PB_INFORMAÇŌES_BÁSICAS_DO_P } \\
\text { ROJETO 768676.pdf }\end{array}$ & $\begin{array}{l}23 / 08 / 2016 \\
23: 54: 09\end{array}$ & & Aceito \\
\hline $\begin{array}{l}\text { TCLE / Termos de } \\
\text { Assentimento / } \\
\text { Justificativa de } \\
\text { Ausência }\end{array}$ & Termo.docx & $\begin{array}{c}23 / 08 / 2016 \\
23: 49: 59\end{array}$ & $\begin{array}{l}\text { BIANCA BARTHOLO } \\
\text { JULIO }\end{array}$ & Aceito \\
\hline $\begin{array}{l}\text { TCLE / Termos de } \\
\text { Assentimento / } \\
\text { Justificativa de } \\
\text { Ausência }\end{array}$ & TCLE.doc $x$ & $\begin{array}{l}02 / 08 / 2016 \\
21: 37: 22\end{array}$ & $\begin{array}{l}\text { BIANCA BARTHOLO } \\
\text { JULIO }\end{array}$ & Aceito \\
\hline
\end{tabular}

Endereço: TERESINA 690

Bairro: SUMAREZINHO CEP: $14.055-380$

UF: SP Município: RIBEIRAO PRETO

Telefone: (16)3602-0009

E-mail: csecuiaba@fmrp.usp.br 


\section{CENTRO DE SAÚDE ESCOLA \\ DA FACULDADE DE MEDICINA DE RIBEIRÃO PRETO -}

Continuação do Parecer: 1.715.152

\begin{tabular}{|c|c|c|c|c|}
\hline Outros & Carta.docx & $\begin{array}{c}02 / 08 / 2016 \\
21: 36: 35\end{array}$ & $\begin{array}{l}\text { BIANCA BARTHOLO } \\
\text { JULIO }\end{array}$ & Aceito \\
\hline $\begin{array}{l}\text { Projeto Detalhado / } \\
\text { Brochura } \\
\text { Investigador }\end{array}$ & Projeto.docx & $\begin{array}{c}02 / 08 / 2016 \\
21: 34: 42\end{array}$ & $\begin{array}{l}\text { BIANCA BARTHOLO } \\
\text { JULIO }\end{array}$ & Aceito \\
\hline Folha de Rosto & Folha.docx & $\begin{array}{c}02 / 08 / 2016 \\
21: 30: 19 \\
\end{array}$ & $\begin{array}{l}\text { BIANCA BARTHOLO } \\
\text { JULIO }\end{array}$ & Aceito \\
\hline
\end{tabular}

Situação do Parecer:

Aprovado

Necessita Apreciação da CONEP:

Não

RIBEIRAO PRETO, 06 de Setembro de 2016

Assinado por:

Amaury lelis Dal Fabbro

(Coordenador)

$\begin{array}{llll}\text { Bairro: } & \text { SUMAREZINHO } & \text { CEP: } & 14.055-380 \\ \text { UF: SP } & \text { Município: } & \text { RIBEIRAO PRETO }\end{array}$

Telefone: (16)3602-0009 